\title{
Adolescents vs. Adults: Does the Criminal Justice System Punish Youth more severely than Adults for the same type of Crime
}

Sheena L. Bowman

West Virginia University

Follow this and additional works at: https://researchrepository.wvu.edu/etd

\section{Recommended Citation}

Bowman, Sheena L., "Adolescents vs. Adults: Does the Criminal Justice System Punish Youth more severely than Adults for the same type of Crime" (2011). Graduate Theses, Dissertations, and Problem Reports. 4698.

https://researchrepository.wvu.edu/etd/4698

This Thesis is protected by copyright and/or related rights. It has been brought to you by the The Research Repository @ WVU with permission from the rights-holder(s). You are free to use this Thesis in any way that is permitted by the copyright and related rights legislation that applies to your use. For other uses you must obtain permission from the rights-holder(s) directly, unless additional rights are indicated by a Creative Commons license in the record and/ or on the work itself. This Thesis has been accepted for inclusion in WVU Graduate Theses, Dissertations, and Problem Reports collection by an authorized administrator of The Research Repository @ WVU. For more information, please contact researchrepository@mail.wvu.edu. 
Adolescents vs. Adults: Does the Criminal Justice System Punish Youth more severely than Adults for the same type of Crime

\author{
Sheena L. Bowman
}

Thesis submitted to the Eberly College of Arts and Sciences at West Virginia University in partial fulfillment of the requirements for the degree of

\author{
Master of Arts \\ in \\ Sociology: Applied Social Research
}

Rachel E. Stein, Ph.D., Chair

Corey Colyer, Ph.D.

James J. Nolan, Ph.D.

Division of Sociology and Anthropology

Morgantown, West Virginia

2011

Keywords: Deterrence Theory, Labeling Theory, Life Course Theory, Adolescents, Adults, Punishment, Property and Violent Crimes

Copyright 2011 Sheena L. Bowman 


\title{
ABSTRACT \\ Adolescents vs. Adults: Does the Criminal Justice System punish Youth more severely than Adults for the same type of Crime
}

\begin{abstract}
Sheena L. Bowman
Understanding the disparity in the amount of punishment between youth and adults, for violent and non-violent criminal activity, remains a matter of theoretical debate. In the present study, the research employs deterrence and labeling theory, through a life course theoretical framework, to assess the extent to which the punishments for violent and non-violent crimes follow different trajectories. The deterrence theory posits an individual will refrain and deter from future offending if the consequence of the crime committed outweighs the actual crime itself. The labeling theory focuses on the labels applied to an individual, and if that label influences the individual's behavior, and promotes future deviant behavior. The life course theory focuses on the connections made in an individual's life and predicts that early events one endures in life can predict their future decisions. This study utilizes the NCRP data set, which consists of questionnaires distributed to inmates in custody for the 2003 calendar year. These data show the amount of punishment given to youth and adults for the same type of crime. Disaggregating by offenses reveals, however, that youth are punished more severely for robbery, aggravated assault, burglary, and larceny. These findings raise questions about the definite effects of the deterrence and labeling process on crime progressions, and suggest the need to continue to investigate the theories that differentiate between youths and adults in relation to specific types of offending.
\end{abstract}




\section{Table of Contents}

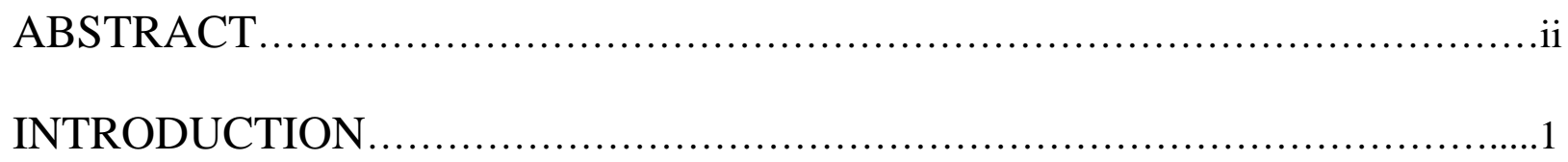

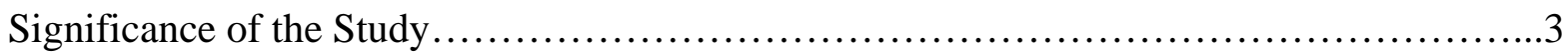

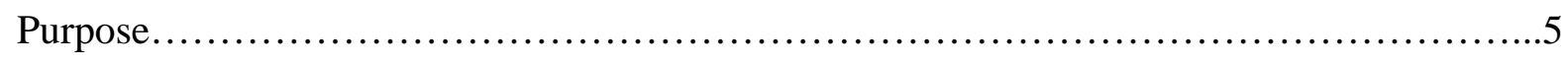

THEORETICAL LITERATURE REVIEW ........................................5

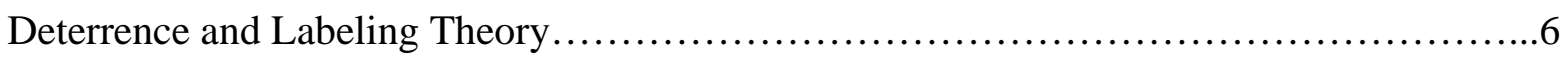

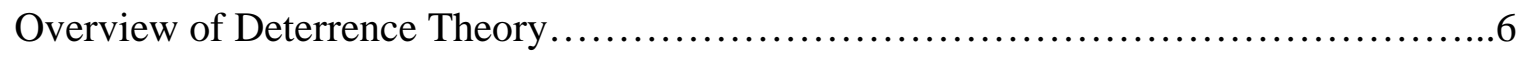

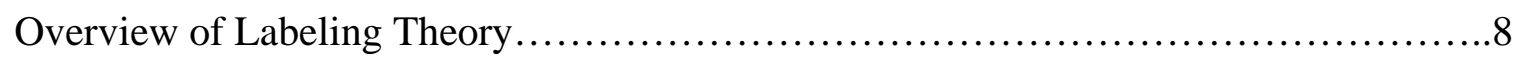

Past Research on Deterrence and Labeling Theory...............................9

Life Course Theory.........................................................12

Overview of Life Course Theory...............................................14

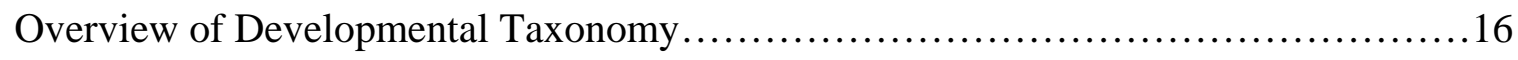

Overview of Multiple Pathways Model.........................................17

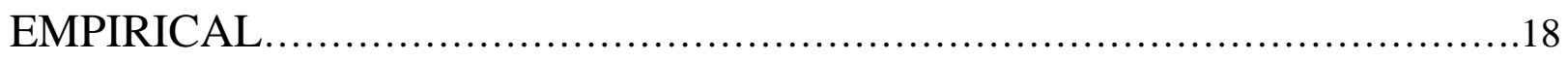

Past Research of Life Course Theory.................................................19

Review of Topical Empirical Literature............................................25

Empirical Review: Importance of Punishment.....................................25

Empirical Review: Importance of Age and Offending..............................28

Empirical Review: Importance of Prior Jail Time................................32

Empirical Review: Demographic Characteristics in Life Course Theory..................33 


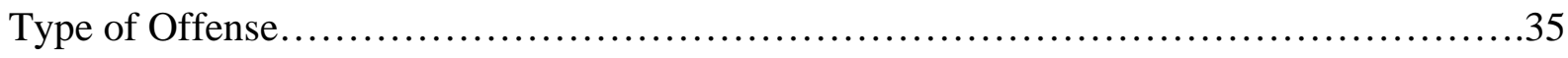

Plan of Study.................................................................

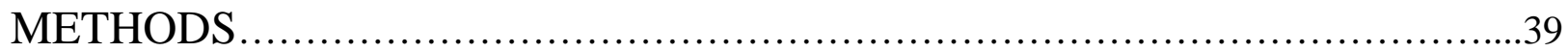

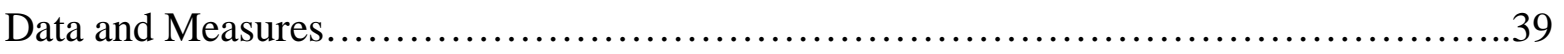

Sample.......................................................................40

Variables.................................................................41

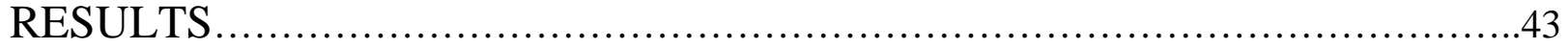

Descriptive Statistics.......................................................43

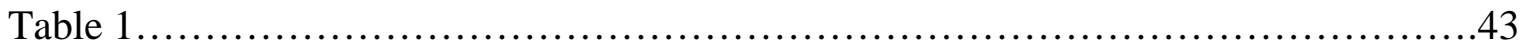

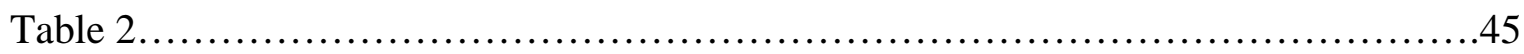

Bivariate Correlation............................................................48

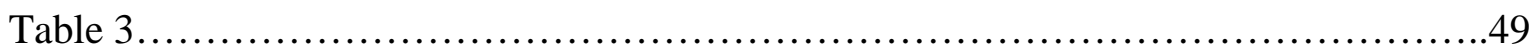

Multivariate Regression.........................................................49

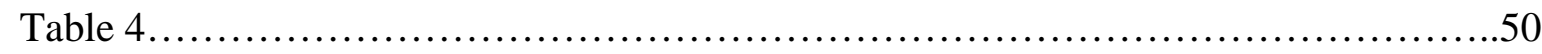

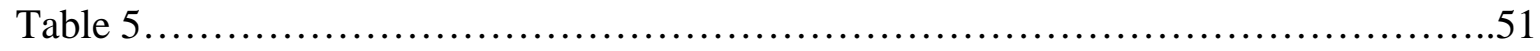

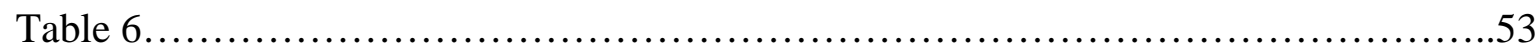

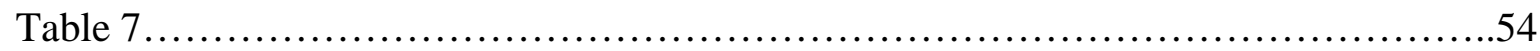

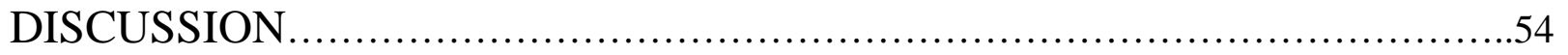

Limitations and Future Research...............................................62

REFERENCES ..............................................................65 


\section{INTRODUCTION}

Past research on crime and delinquency has essentially included age as a variable to predict future crime. Much of the research has proven the significant relationship between age and crime. However, various studies have provided dissimilar findings of the type of age groups that commit the most crime, and the amount of punishment given to an individual based on their age. According to past research, authors argue the amount of criminal behavior generally peaks in early adulthood (Sampson and Laub1993; Moffitt 1993). Past research, also, demonstrates that significant punishment is not enforced for many offenders until they reach their midtwenties, the time researchers argue offenders are at the near end of their criminal activity (Moffitt 1993). Recent research, however, reveals that most crime is committed by offenders at a young age, either as juveniles or young adults (Bacon et. al 2009; Francis et. al 2007; Bouffard and Piquero 2003). Also, recent research disputes that adolescents are punished more severely than adults for the various types of crime they commit to deter future offending (Ash 2006). Although, discrepancy between past and present research on age and crime is both accounted for in the current research, the deterrence and labeling theory, along with elements from the life course theory, are guidance to represent a groundwork relationship between age and punishment.

People in society are inclined to engage in deviant activities if they do not fear apprehension and harsh punishment for their consequences (Kleck et al. 2005). Laws are implemented for acts of criminal behavior to support the image that negative behavior involves consequences and punishment. The deterrence theory affirms that subsequent criminal offending rates decrease for an individual based on the type of punishment he or she received for the type of crime committed (Kleck et al. 2005). The labeling theory states that misdiagnosed deviant 
labels applied to an individual influence their behavior and promote continuous deviant behavior (Bernburg et al. 2006). For example, a teen labeled as a delinquent may fulfill the negative label placed upon them and proceed to behave strictly as a criminal. In theory, youth labeled as criminals consider themselves criminals and accept they are people who do not abide by the law in society (Paternoster 1989). The life course theory states that an individual desists from criminal activity as the individual ages. In theory, the life course theory posits that individuals commit crime at a relatively younger age, possibly with peers, and as the individual ages he or she learn that criminal behavior is not accepted in society (Sampson and Laub 1993).

In the present study, the deterrence theory provides guidance to explore whether youth receive a harsher punishment than adults to eliminate future offending. The labeling theory provides a framework that younger individuals are punished more severely than adults, which stigmatizes their image as a criminal and causes the individual to repeat crime. The life course theory provides guidance to explore punishment as a transition in an individual's life. The theories, outlined above, provide fundamental support for the current hypothesis that youth are punished more severely than adults for the same type of crime. The deterrence theory supports the current hypothesis because a harsher punishment at a young age deters future criminal behavior. The labeling theory supports the current hypothesis that after a criminal label becomes branded on an individual they accept that label and continue to behave as a criminal. The life course theory supports the research because a harsh punishment for young offenders at their first conviction may cause them to desist from crime at an earlier age in their life. The current study divides up the offender population to focus on the amount of punishment imposed on both youth and adults. Additionally, the current research explores the relationship between the age of an 
offender and the amount of punishment he or she receives based on a specific type of property and violent crime.

\section{Significance of the Study}

It is beneficial to address the changes the Criminal Justice System (CJS) have made, in regards to the amount of punishment youth receive in attempts to better understand the significance of the amount of punishment for adolescent offenders. "Adolescence is a transitional phase of development that occurs between childhood and adulthood" (Ash 2006). Specifically, adolescence was not recognized as a separate life stage until the end of the $20^{\text {th }}$ century, when legislatures feared a new breed of "superpredators" would be responsible for the increase in the amount of crime (Bilchik 2000).

In the late 1980s and early 1990s, crime rates for adolescents escalated (Bilchik 2000). Criminologists predicted the crime rates would continue to climb based on the increase of juvenile population; however, evidence represented that juvenile crime only increased for a few years in the 1990s, and then returned to a level that was reported in previous generations (Ash 2006; Bilchik 2000; OJJDP 2000). In the 1990s, researchers advocated a theory of the emergence of a generation of young, violent superpredators in the upcoming century. The theory gained credibility from a series of highly publicized violent youth crimes, due to the demographic projections of a growing juvenile population, as well as an increase in juvenile arrest rates. However, after the theory was accepted, the Office of Juvenile Justice and Delinquency Preventions (OJJDP) conducted a study that omitted the superpredator theory as an explanation for juvenile crime (OJJDP 2000). 
Throughout the debate for the rise of juvenile superpredators, nearly every state altered their laws to securely punish youth as an adult (Ash 2006). Despite there was no validity to the superpredator theory, there have been no changes in the laws that were previously put into effect to punish youth more freely as an adult. Since 1992, every state in the US, with the exception of Nebraska, has expanded their provisions to transfer adolescents directly to adult court (Ash 2006). Transfer laws execute several methods by lowering the age, at which an adolescent is considered an adult, from 18 to 17 (in some instances 16), and also includes statutory exclusion (Sickmund 2003; Ash 2006).

There have been countless debates as to how the CJS should properly and adequately punish an adolescent for an act that is deemed a crime for an adult. "Adult time for adult crime" is a phrase that reflects a poor understanding to the root principles of the CJS (Brame et al. 2004). If the specific punishment is to fit the crime, then both the nature of the offense and the moral responsibility of the offender must be recognized (Ash 2006; Brame et al. 2004). "As the U.S. Supreme Court has repeatedly recognized, the blameworthiness of children cannot be equated with that of adults, even when they commit the same crime” (Saltzman 2004). In 2005, the U.S. Supreme Court ruled in Roper v. Simmons that juveniles "lack the unkind identities of adults, display irresponsible behavior, and are defenseless to negative peer pressures” (Roper v. Simmons 2005).

The significance of the current study is to determine if the CJS implements a harsher punishment for younger individuals based on the same type of crime. It is important to address the amounts of punishment because past research displayed the CJS punished youth as adults to deter future offending in an individual's life course (Ash 2006). Precisely, it presents data from 
the National Corrections Reporting Program (NCRP) that displays the amount of punishment for both younger and older individuals, in efforts, to determine if the court systems have punished youth as adults, or very similar to adults, to deter future offending.

Purpose

Although, the different types of punishment enforced for adolescents remains to be a debatable topic, researchers agree that punishment is necessary to deter future criminal behavior. The current research focuses on the role of past punishment for youth and seeks to identify whether the CJS has, undoubtedly, adopted a more punitive stance. Specifically, the amount of punishment between younger and older offenders is compared across specific violent and property types of crime, to better explain if younger individuals received a harsher punishment than older individuals for a specific type of crime.

\section{THEORETICAL LITERATURE REVIEW}

The deterrence theory posits that individuals deter from crime after a harsh punishment is enforced. The theory argues that laws are applied to individuals after they commit a crime to inform individuals they must abide by the laws to protect and maintain order in society (Nagin et al. 1998; Watkins et al. 2008). The labeling theory posits that deviant labels applied to an individual influence their negative behavior and promote future deviant behavior. In theory, youth are labeled as "bad people" in society and become rebellious after they accept the negative label that society deemed upon them (Bernburg et al. 2006). The life course theory posits that individuals desist from crime as he or she ages. Outlined below, are elements from the deterrence, labeling and life course theory that assist in the explanation of the current hypothesis. 


\section{Deterrence and Labeling Theory}

\section{Introduction}

Considerable research has been completed on the many aspects of the deterrence and labeling theories. Studies have examined the effects of court convictions, as a deterrent, on both youth and adults convicted in the CJS. Past research has studied the impact of subjective perceptions of a court hearing on subsequent offending to determine if a harsh conviction is used as a deterrent for recidivism (McGrath 2009). However, minimal effects are known about the actual operation of the deterrence process. The current research utilizes elements from the deterrence theory to better support the hypothesis that younger offenders are punished more harshly than older offenders for the same type of crime to deter future offending into adulthood.

Past research on labeling theory has frequently examined if contact with the CJS employs a negative effect on offenders. Researchers imply that negative contact with the CJS stigmatizes the individual and increases the likelihood of recidivism (McGrath 2009). However, there remains unexplored foresight to determine if contact with the CJS leads to future reoffending for individuals. The current study draws on elements from the labeling theory to better support the hypothesis that younger offenders are punished more harshly than older offenders for the same type of crime, in efforts, to explain that offenders with prior incarcerations are subsequently deemed a criminal.

Overview of Deterrence Theory 
The past perspective of criminological theories states severe punishment is an aid in the desistance of future criminal activity (Saltzman et al. 1982; Blumstein et al. 1988; Nagin 1998). Deterrence theory posits a concept that harsh punishment causes an individual to feel threatened by sanctions and deter from continuous criminal activity (Blumstein et al. 1988; Nagin 1998). Previous deterrence theory research states the effect of incarceration on an individual at a young age leads to future deterrence from criminal behavior. The overall debate of the deterrence theory is the impact incarceration employs on an individual's criminal career, and if the criminal activity would resume at the same level, increase, or possibly decrease after the individual has been incarcerated (Nagin 1998).

General deterrence theory asserts that people engage in criminal activity because they do not fear the punishment after the crime (Pogarsky 2007). The overall goal of general deterrence is to reduce the probability of deviance within the population. General deterrence focuses, primarily, on the prevention of future criminal behavior through punishment (Nagin 1998; Pogarsky 2007). Specific deterrence focuses on harsh punishment for criminals to prevent the criminal from future offending (Nagin 1998; Pogarsky 2997). The overall goal of specific deterrence is the use of punishment to eliminate deviant behavior. "Research demonstrates that recidivism rates amongst convicted felons is around $63 \%$ higher immediately after release from prison, and that majority of prisoners have previous convictions prior to their current offense" (Bureau of Justice Statistics 1989). Although, prison as a form of punishment does not necessarily alter future behavior, it does, however, reduce the likelihood that individuals engage in future offending (McGrath 2009). The deterrence theory relates to the current research 
because the hypothesis states younger individuals are punished more severely than older individuals to deter future offending.

\section{Overview of Labeling Theory}

The labeling theory posits that deviance is not a quality of the criminal act committed, but is the result of personality factors associated with deviance committed (Paternoster et al. 1989). The theory hypothesizes that misdiagnosed labels applied to an individual influence decisions and promote deviant behavior through stigmatization. The main concern of the theory is to focus on how the self-identity and behavior of individuals influence the terms used to classify their image (Paternoster et al. 1989; Gove 1980; Bernburg et al. 2006). Individuals are aware of how they are judged by others because they can read the reactions people present when they are amongst social interactions. More importantly, political officials are more apt to label a one-time offender as a criminal, which, in turn, could alter their mentality.

The labeling theory focuses on the stigmatizing effects from labels for juvenile criminals. The labeling theory specifies that criminal labels stigmatize juveniles and, in turn, they transform into delinquents to fulfill the label placed upon them by society (Paternoster et al. 1989;

Bernburg et al. 2006). Juveniles learn to accept the labels that society, or the CJS, placed upon them and misbehave as criminals in society. Specifically, the labeling theory proposes youth begin to adapt to their label of a criminal and transition into a criminal lifestyle of behavior (Bernburg et al. 2006). Overall, the labeling theory asserts that contact with the CJS causes an increase in future offending, due to stigmatizing effects (McGrath 2009). The labeling theory 
relates to the current research because prior incarceration for youth stigmatizes them as a criminal; therefore, the individuals learn to accept the label and continue to offend.

\section{Past Research on Deterrence and Labeling Theory}

Past studies have taken elements from the deterrence and labeling theory and applied them to individuals that commit deviant acts of crime. McGrath (2009) tested the impact of deterrence and labeling theories on recidivism rates. The author proposed two hypotheses: (1) participants who believed themselves to be at lower risk of arrest in the event of future criminal activity should be more likely to be reconvicted; and (2) participants who believed they received a more severe sentence at their current conviction are less likely to be reconvicted. The sample consisted of 206 interviews at the New South Wales (NSW) Children’s Court, in Sydney, Australia, between September 2004 and December 2005. Interviews were conducted immediately after each participant's sentencing for their current offense. The dependent variable in the study was measured as recidivism, and the recidivism data were obtained from the reoffending database (ROD). The author examined three groups of independent variables: (1) "hearing and sentencing, which included perceived certainty, perceived severity, measures of deterrence, and sentence and offense variables; (2) reintegrative shaming, which included stigmatization, reintegration, procedural fairness, and shaming; and (3) background controls, which included socio-demographic variables, developmental, social attachment, and current social context.”

McGrath’s (2009) findings displayed that both perceptions of deterrence and stigmatization play an important role in an individual's recidivism rate. McGrath (2009) 
discovered from his study that the sentence received at the NSW Children's Court did leave an impact to both prevent and increase future offending. Overall, the author's evidence supported the deterrence theory because individuals, who reported the harsh sentence received, as well as the risk of harsh apprehension in the future, eliminated criminal offending in the future. However, the author did not find much support for the labeling theory because individuals who felt stigmatized were more likely to reoffend. The study conducted by McGrath (2009) relates to the current research because I measure prior incarceration for each offender in the sample. Also, it offers support for the current hypothesis that youth receive lengthier sentences to deter future offending.

Another study that tested the labeling theory to examine arrest rates was Tapia (2010). The author's data were observed from the ongoing National Longitudinal Survey of Youth (NLSY 1997), which consisted of 8,984 U.S. youths between the ages of 12 to 16 . The author collected information based on the individual's delinquency levels, arrests, and other legal and social indicators through youth self-reports. The dependent variable in his study was the number of new arrests reported. The independent variables were forms of delinquency (coded as minor delinquency or serious delinquency). Minor delinquency consisted of substance use items (alcohol, marijuana, cocaine or other hard drugs) and vandalism (number of times youth destroyed property). Serious delinquency consisted of assault (number of times youth caused bodily harm to others), property crime index (minor theft, major theft, and handling stolen property), and drug sales (any involvement in drug sales). The author measured race and ethnicity as dummy variables for White, Black, and Hispanic respondents, with Whites as the omitted race category. Also, SES was measured in two waves, as well as gender and age. 
Tapia (2010) proposed three hypotheses: (1) racial minority status increased arrest risk when controlling for demographic (delinquency) and legal variables (arrest history); (2) SES predicts arrests when controlling for race, demographic, and legal variables; and (3) interaction of minority status and low SES increased arrest risk. Tapia (2010) found that race effects were more apparent in petty crimes where police employed more discretion in their arrest decision. Overall, the author presented data to support the delinquency literature that minority youth engage in more assaultive behaviors, accumulate lengthier criminal records, and were more likely to be of a lower and middles SES. Although, the current study does not measure an individual's SES, or arrest risk, the study does, however, measure prior incarceration to determine if the individual possessed prior convictions before their current offense. Also, the current study specifies specific types of violent and property crimes to examine the amount of punishment when convicted at their current age.

Watkins et al. (2008) examined the deterrent effects of legal punishment for individuals that carry a gun for violent behavior. The authors included measures of perceptions for the risk of arrest and the outcome over the legal punishment for gun use. Furthermore, the authors extended the research to assess effects of perceived sanction risk on gun-related behaviors among incarcerated individuals. Data for the study were obtained from a larger firearm research project in St. Louis, and consisted of males placed in adult jails and juvenile detention facilities between the years of 2003 and 2007. The sample of males completed surveys that contained both open and close-ended questions over the four year span. The total sample size for the study consisted of 629 adults and 338 juveniles. There were three dependent measures in the study: (1) gun possession; (2) frequency of gun carrying; and (3) gun use. The authors examined race, age, 
prior criminal history, and gang membership as demographic characteristics, as well as the type of arrest for the individual's current conviction.

The authors' findings displayed that majority of offenders had previous contact with the CJS prior to their current arrest (Watkins et al. 2008). Watkins et al. (2008) found that more than half of the respondents indicated they were frightened by harsh penalties associated with crime, but less than half of juveniles (39 percent) and adults (24 percent) reported they actually considered the outcome of the punishment when the crime was committed. In regards to the juvenile sample, their study suggested the deterrent effect of arrest was more beneficial for youth who were only marginally involved in deviant acts. Also, in regards to the juvenile sample, the authors displayed there was no deterrent effect of punishment for juveniles that were previously involved with deviant acts. Overall, their results discovered that juveniles were less likely to deter from criminal acts after they began deviant behavior. In regards, to the adult sample, their study represented that adults were more receptive to deterrent effects. The study of Watkins et al. (2008) relates to the current research because prior incarceration is a control variable for different age groups.

\section{Life Course Theory}

\section{Introduction}

There has been considerable research analyzed on the many aspects of the life course theory. Studies have examined transitions and trajectories, adolescent limited and life course persistent offenders, and various pathways to crime to explain crime and age (Sampson and Laub 1993; Moffitt 1993; Loeber and Hay 1997). However, these studies have consistently lacked in a 
theoretical examination of how the amount of punishment differs between adolescents and adults for specific types of crime to better explain the relationship between age and punishment. There are elements from three specific theories to guide in the explanation of the age-punishment relationship: (1) age graded life course theory; (2) developmental taxonomy; and (3) multiple pathways model. Sampson and Laub’s age graded life course theory concludes there are both continuity and change that exist throughout an individual's life and that modifications in individual behavior may occur through new social circumstances (Sampson and Laub 1993). Moffitt's developmental taxonomy theory posits there are two types of offenders: (1) life course persistent offenders; and (2) adolescence limited offenders (Moffitt 1993). The multiple pathways model estimates that involvement commonly begins with less serious crime, and in turn, leads to more serious criminal behavior as individual's age in life (Loeber and Hay 1997).

The elements from the age graded life course theory that provide a beneficial framework for the current research, are trajectories and transitions. It is important to focus on trajectories because it explains continuity in an individual's life. Trajectories are beneficial elements to the current study because prior incarceration could represent continuity in crime for an individual; it may also represent more continuity in crime for either adolescents or adults. It is important to focus on transitions because it explains a single event. Transitions are beneficial elements to the study because it represents the amount of punishment an adolescent or adult received for a specific type of crime. The beneficial element from the developmental taxonomy theory is the focus on the two types of offenders - the life course persistent and adolescence limited offenders. Although, the current research accounts for previous incarceration of jail time, the focus on the two types of offenders assist in the explanation that prior incarceration has an 
impact on the amount of punishment for an adolescent and an adult. In the current study, the multiple pathways model assists to explain if offenders with a prior incarceration record are more likely to continue future offending through a specific pathway.

In the following theory sections, outlined below, there is an overview of particular elements from each theory that provide a framework in the current study. The life course theory demonstrates the importance of time to explain the relationship between age and punishment. The developmental taxonomy theory assists to explain if individuals with a history of prior incarceration receive a longer punishment based on their age. Elements from the multiple pathways model are very similar to the developmental taxonomy elements, because prior incarceration for young offenders could affect a longer amount of punishment on their current offense. In addition, following the theory sections outlined below, past research presents analyzed elements from the life course theory, due to the very similar variables that are a measure in the current research.

\section{Overview of Life Course Theory}

Beginning with the life course theory, it is important to focus on the relationship between age, type of crime, and the amount of punishment for the crime. The life course perspective emphasizes the importance of time, social context, and process, in both theory and analysis, because it accounts for historical events and changes that occur throughout an individual's life (Sampson and Laub 1993; Piquero 2005). According to Sampson and Laub, the life course perspective provides a broad framework to study lives over time and are more specifically applied to crime (Piquero 2005). 
There are two central concepts in the life course theory: (1) trajectories; and (2)

transitions. Trajectories are the long-term patterns and sequences in an individual's life, such as criminal or non-criminal behaviors (Sampson and Laub 1993; 2003). Transitions, incongruously, occur within trajectories and are single events that are age graded, such as changes in societal roles or status (Sampson and Laub 1993; 2003). Unexpected life events in an individual's life can be influential and transform life trajectories; therefore, there is a sequence of life trajectories, transitions, and adaptations throughout the life course (Piquero 2005).

Another objective of the life course perspective is continuity and change in behavior over time by linking past events and experiences to the present (Piquero et al. 2003). The central concern is the extent of continuity in behavior between childhood, adolescence, and adulthood (Sampson and Laub 1993; Piquero 2005). At the same time, the life course perspective focuses attention on turning points, which also modify life trajectories in unexpected ways. The advantage of the life course perspective is that it recaptures an individual's childhood; and, it recognizes that individual behavior is intervened over time, through interaction with age-graded institutions to develop and implement a theoretical model, that accounts for crime and deviance in childhood, adolescence, and adulthood (Sampson and Laub 1993; 2003).

Importance of time, continuity into adulthood, and a turning point in an individual's life are important theoretical ideas from the life course theory that guide in the link between age and punishment in the current study. For example, there is a possible link between the importance of time and punishment because the CJS may punish youth more severely at a younger age to represent an important time to learn that criminal behavior is neither tolerated, nor accepted, in society. In addition, the reasoning behind the systems decisions for punishing youth more 
severely for a crime at a younger age is to deter future continuity of offending in adulthood. Harsh punishment for youth at a young age may yield as a turning point for that individual to desist from crime because they do not want to spend their life incarcerated. In the current study, it is important to link age and punishment because the specific crime committed is a single transition in an individual's life and severe punishment could prevent criminal continuity into adulthood. The amount of punishment could be a turning point for an individual to age out of crime.

Overview of Developmental Taxonomy

Moffitt's theory of developmental taxonomy originates with the classic aggregate agecrime curve, which exhibits a peak in late adolescence, followed by a sharp decline throughout early and middle adulthood, and then finally diminishes in later adulthood (Moffitt 1993). Moffitt states the aggregate age-crime curve hides two distinct groups of offenders: (1) adolescence limited offenders; and (2) life course persistent offenders. Adolescence limited offenders are characterized by highly active, short-term participation in the adolescent years (Moffitt 1993). Life course persistent offenders are characterized by a small subset of individuals who engage in criminal activity at fairly frequent rates throughout most of the life course (Moffitt 1993).

The adolescence limited group of offenders learns to offend during the adolescent time largely because of the peer social context that emerges in adolescence (Moffitt 1993). Because of this maturity gap, adolescents seek the comfort of one another and engage in acts that seek to relieve them of their situation, such as vandalism and minor forms of theft (Moffitt 1993). After an adolescent reaches adulthood, they tend to function as normal adults with careers, 
relationships, and so forth. Moffitt states that only among a small number of adolescence limited offenders, does criminal activity continue into adulthood. The life course persistent offenders begin their involvement in criminal activity early in the life course. This particular group of offenders offends at stable rates throughout their adolescent years and continues to offend into their adulthood years (Moffitt 1993). "Unlike the peer social context, life course persistent offending is a function of cognitive problems that are formed early in an individual's life course" (Moffitt 1993).

In sum, Moffitt’s theory suggests that adolescents are not worthy of harsh punishment because they are more apt to desist from crime as they age; however, life course persistent offenders offend throughout their life and are entitled to harsher punishments. These elements are a guide in the current study to examine the amount of punishment for an offense over all age groups. Specifically, the elements of guidance from Moffitt's theory are the measure that accounts for prior jail incarceration. Moffitt's theory proposes that young offenders, with a record of previous incarceration, receive a longer sentence for their punishment to prevent the adolescent offender from becoming a life course persistent offender.

\section{Overview of Multiple Pathways Model}

A more in depth explanation for the relationship between adolescence and crime is Loeber and Hay’s multiple pathways model. Loeber and Hay developed a three-pathway model to portray developmental sequences in three domains: (1) overt behavior problems; (2) covert behavior problems; and (3) problems with authority figures. The overt pathway begins with minor aggression, followed by physical fighting, and then violence (Loeber and Hay 1997). The covert pathway consists of a sequence of minor covert behaviors, followed by property damage, 
and moderate to serious forms of delinquency (Loeber and Hay 1997). The authority conflict pathway, which is prior to age 12, consists of a sequence of stubborn behavior, defiance, and authority avoidance (Loeber and Hay 1997).

According to the three-pathway model, individuals begin at a lower order and then proceed through the hypothesized sequences (Loeber and Hay 1997). It is also possible that an individual's development can take place on more than one pathway, and some youth progress on all three pathways (Loeber and Hay 1997; Piquero and White 2003). The most frequent offenders are overrepresented among individuals in multiple pathways, especially those that display both overt and covert behavior problems (Piquero and White 2003).

In the current study, the specific pathway for an individual is not identified because the data is concentrated on the amount of punishment for a specific type of offense based on age. Specifically, in the current study there is a measure of age, prior incarceration, and type of offense that assist in the explanation of pathway an individual would be categorized based on their age, prior jail time, and whether the offense was violent or property. For example, the theory suggests that a young violent offender with prior jail incarceration is more likely to be at risk to become a future offender. It is important to measure for prior incarceration because it is the main element taken from Loeber and Hay's theory that relates to the age and amount of punishment relationship in the current study.

\section{EMPIRICAL—Framed around Life Course Theory}

Past studies have seized elements from the life course theory and applied it to research in different ways, such as an explanation to deter future offending. Loughran et al. (2009) focused 
on transition and trajectory elements from the life course theory to test whether recidivism rates were greater for those youth who received institutional placement, as opposed to those youth placed on probation (Loughran et al. 2009). The current research does not specifically tests the recidivism rates of offenders; however, it examines prior incarceration and considers the importance of age as a trajectory. The authors' results stated the juvenile court tends to lead toward a more punitive-oriented orientation (Loughran et al. 2009), with "get-tough” policies that were perhaps not as entirely effective as hoped for by proponents. The authors stated there was minimal benefit from increased deterrence connected with either placement out of the community, or longer stays in institutions (Loughran et al. 2009). Cauffman et al. (2004) argued "that in the context of the boundaries of the juvenile court, developmental differences among offenders may lead to different responses, either positive or negative, to an otherwise uniform treatment." For example, "placement is problematic if it labels, and thus stigmatizes less serious offenders and prevents individual's successful reintegration into roles connected with a successful transition into non-offending adulthood” (Cauffman et al. 2004).

To better understand the criminal career elements from the life course theory, Bouffard and Piquero (2003) examined defiance theory from a life course perspective for the individual's first encounter with police and their criminal careers. Their data explained continuity in offending over the life course, which contained information in reference to the offending behavior of an individual, as well as the person's perceptions about his or her encounters with police (Bouffard and Piquero 2003). The primary focus of the authors' research explained whether or not individuals continued to offend throughout their life course. Information provided the total number of police contacts for each sample member, as well as the age of their last 
official contacts. The authors' study provided the first attempt to test Sherman's (1993) defiance theory (Bouffard and Piquero 2003). The authors' analyses addressed the four key features of defiance in a longitudinal framework. Their findings reported that groups characterized by defining the sanction as "unfair and poorly bonded" experienced higher rates of offending and slower desistance over the life course, as compared to those who perceived their treatment as “fair or well-bonded.” The research of Bouffard and Piquero (2003) relates to the current study because any youth with a prior incarceration record may suffer from stigmatization, due to their first initial contact with police, and in-turn, cause higher rates of offending over their life course.

Previous research that examined the life course theory to better explain offending, the age of onset and a criminal career is Bacon et al. (2009). The authors' first estimation model only included the age of onset offending, along with control variables for age, race, and census tract socioeconomic status. In the authors' second model, the sample included unmeasured criminal propensity and examined what happens to the initial age of onset effect. In addition, for the range of onset ages between 8 and 16, the authors estimated the effect of each age of onset for subsequent criminal activity.

According to the findings of Bacon et al. (2009) only a small percentage (6.1 percent) of their sample initiated or exhibited involvement in criminal offending before the age of 10 . Among those who did commit an offense, majority were older than 14 years of age, and the model ages of onset were 15 and 16 years of age. The authors also found the peak ages of offending were 15 and 16. At age 17, however, the percentage of the cohort that initiated offending and exhibited involvement in offending began declining (Bacon et al. 2009). The link 
between the research of Bacon et al. (2009) and the current study is that adolescents purposely receive a harsher punishment, over adults, to deter future offending.

While Loughran et al. (2009) demonstrated the length of time youth spent in institutional placement was not linked to a decrease in recidivism, other researchers highlighted that the official contact with the CJS is more affective for juvenile offenders than adult offenders. For example, Wiesner et al. (2003) emphasized the role of the CJS, as a source of intervention for youthful offenders, and noted a relationship between juvenile arrests and career outcomes. Wiesner et al. (2003) compared past juvenile arrests to career outcomes. The analyses were conducted using data from the OYS, an ongoing multi-agent and multi-method longitudinal study (Wiesner et al. 2003). In their study, the authors recruited a sample of boys from schools located in the higher crime neighborhoods of a metropolitan region in the Pacific Northwest. The authors classified the boys to be at risk for developing subsequent delinquency (i.e., an at-risk sample), by virtue of living in higher crime neighborhoods (Wiesner et al. 2003). Their study examined prospective effects of involvement with the CJS on two employment outcomes for 203 at-risk young men.

In the study, the authors determined the effects of official contact with the CJS were significant for juvenile arrests, but not for adult arrests. There is a possible connection between the research of Wiesner et al. (2003) and the current study because their research states that contact with the CJS is significant only for juvenile arrests, which offers support there is a possibility the deterrence theory is an affective form of punishment. The current study controls for prior incarceration, which represents if an adolescent had previous contact with the CJS; 
because, prior incarceration for adolescents may cause an increase in the amount of punishment for their current offense.

Similar to Wiesner et al. (2003), but contradicting to Loughran et al. (2009), Stahlkopf et al. (2008) proposed that an increase in incarceration length prevented offending later in adulthood. The authors argued an increase in incarceration rates for adolescents was a form of deterrence for future incarceration rates. In the past 25 years, the California Correctional Policy has developed a strategy that an increase in incarceration rates produces a decline in crime rates (Stahlkopf et al. 2008). Their study yield results that the long-term analysis of major crimes committed by all age groups during the past 25 years, represent that crime rates skyrocketed among adult age groups, specifically ages 40 to 59, while youth crime rates declined (Stahlkopf et al. 2008).

Stahlkopf et al. (2008) proposed the California Correctional policy created an increase in incarceration rates to produce an overall decline in crime rates. The hypothesis for the current study relates to the authors' hypothesis because the researchers found that an increase in incarceration is used as a deterrence factor to prevent future offending. Similar to the focus on the amount of punishment in the current study, Stahlkopf et al. (2008) examined how the CJS increased the length of incarceration to deter future crime. Their article informs the current hypothesis because the NCRP data set may display a harsher punishment for youth over adults, in efforts, to deter future offending.

Similar to the focus of trajectory elements from the life course theory, a study by MacDonald et al. (2009) observed previous analytical frameworks and provided a modeling 
procedure that examined those theoretical issues. The authors' research tested whether longitudinal trajectories of violent and non-violent criminal behavior were the same among a sample of adolescents at risk for serious criminal offending. The authors' disaggregated offending into violent and non-violent crime and estimated two stages of analyses. The first stage involved estimating separate group-based offense trajectories for violent and non-violent crime. Additionally, this stage examined whether group membership in both sets of trajectories were explained by the same set of risk factors, and the level of concordance between individuals sorted into violent and non-violent trajectory groups.

The second stage involved an estimation of a joint trajectory model for the two outcomes. Together, these two sets of results assisted in the investigation for the existence of differences in offending pathways for violent versus non-violent crimes, and "shed some light on the necessity for general versus behavioral distinct approaches to studying criminal offending” (MacDonald et al. 2009). Most importantly, their analysis indicated that patterns of violent and non-violent offending were most closely approximated with a three-group trajectory classification, and that membership in offending groups was not statistically independent at the individual level. However, when modeled jointly, there was substantial overlap in the trajectories of both offense types (MacDonald et al. 2009). The authors' research is important to the current study because age may affect the type of offense committed, as well as affect the amount of punishment for that type of crime.

Several researchers have concentrated on the criminal career aspect of the life course theory (Bacon et al. 2009; Bouffard and Piquero 2003; Francis et al. 2007). While not the focus of the current study, a review of this research relates to the current study because the primary 
focus is on age, crime, and punishment. To examine the length of an individual's criminal career, Francis et al. (2007) examined elements from the life course theory for a better explanation in the length of time an individual spent as a criminal. Francis et al. (2007) proposed two main goals in their study. The first, to model criminal career length using data from six different British birth cohorts, over a 25-year period; and second, to attempt to understand whether information available at the first court appearance leading to a conviction was associated with the length of a criminal career (Francis et al. 2007). To estimate career length, the authors tested data from the British Offenders Index (OI). The OI database for England and Wales contained information on all court convictions since 1963, and included information on gender, age and date of each conviction, detailed offense codes, and sentence awarded. The authors' research relates to the current study because the amount of punishment enforced for adolescents may present increasingly harsher than the amount of punishment enforced for adults to deter future criminal careers.

Past research has displayed that specialization varies both with offender age and across offense types (Blumstein et al. 1988; Stander et al. 1989; Armstrong 2008). Despite the close relationship between age and the number of offenses, research on specialization has not attempted to assess the extent to which trends in specialization have changed with age (Armstrong 2008). Armstrong addressed this gap in the life course literature through assessment of the extent to which controlling for age accounts for trends in specialization across arrests. Armstrong (2008) “studied a sample of serious offenders to contrast trends in specialization across arrests, after the observation of age, to assess the extent to which age accounts for trends in specialization across arrests." "If age influences trends in specialization across arrests, then 
trends prior to controlling for age differs from the trends in specialization that remain once age was accounted for” (Armstrong 2008).

The analysis revealed that, although, controls for age did not account for trends in specialization across all types of offending, age did appear to have an important influence on trends in specialization for particular offense types (Armstrong 2008). The main component of the current research is the examination of age- - youth and adults — to measure the amount of punishment an individual receives from the crime committed. For example, a 14-year-old may receive a harsher punishment for aggravated assault, whereas a 30-year-old may have the same charge and receive a less or more severe punishment. The current study relates to Armstrong's research because he presents that specialization in specific arrests is most likely influenced by age.

\section{Review of Topical Empirical Literature}

The main hypothesis of the current research is the CJS punish youth more severely than adults for the same type of crime. Not only does this research examine the amount of punishment for a crime depending upon age, it also specifies the type of crime a specific age group commits. For example, the current research examines specific violent and property crimes to explain whether the amount of punishment varies across different age groups for specific types of crime. Past research, outlined below, has tested similar dependent, independent, and control variables that is measured in the current study.

Empirical Review: Importance of Punishment 
A common theme in crime is the amount of punishment an individual receives for the type of crime. There are three articles, outlined below, that study punishment and rates of offending to better explain the amount of punishment for youth and adults. Similar to the focus on the length of punishment in the current study, Loughran et al. (2009) examined how the length of stay in institutional placement affects youths' rates of recidivism. Although, researchers have not specifically concentrated on the length of punishment and its effect on youths rates of recidivism, their research indicated that youths official contact with the CJS is importantly related to career outcomes (Wiesner et al. 2003), and future criminal behavior (Stahlkopf et al. 2008).

Loughran et al. (2009) identified two related, yet distinct treatment effects: (1) the effect of placement, as compared with probation, on subsequent rates of offending; and (2) the marginal effect of length of stay in placement. The authors' tested whether recidivism rates were greater for those youth who received institutional placement, or greater for those youth that were placed on probation (Loughran et al. 2009). Loughran et al. (2009) highlighted whether the subsequent rates of offending, among those youth placed in institutions, declined as a function for the length of stay in those institutions. The authors examined a subset of the research participants recruited for the Pathways to Desistance Study, which is an ongoing longitudinal investigation of the transition from adolescence to young adulthood, in serious adolescent offenders (Loughran et al. 2009). Loughran et al. (2009) focused on youth who resided in Maricopa County, AZ, and Philadelphia County, PA.

The main objective of the research conducted by Loughran et al. (2009) was to test whether boys placed in placement had a higher chance of recidivism, as opposed to those placed 
on probation, as well as if the length of stay in placement had a less chance of future recidivism. The current research focuses on the amount of punishment for adolescents and adults and whether the punishment enforced is greater for youth or adults based on the same crime. Comparable to Loughran et al. (2009), the current research examines adolescents who were found guilty of a serious offense in the adult court systems.

Loughran et al. (2009) extended the discussion of how serious juvenile offenders responded to placement and longer stays out of the community. The authors focus on "gettough” polices is important for the current study. The current study hypothesizes the CJS punish youth more severely than adults for the same type of crime to reduce the amount of crime an individual commits throughout his or her life. However, the authors conclude there was no effective link between the amount of punishment and deterrence for future offending (Loughran et al. 2009). Furthermore, the authors conclude that a more punitive punishment for younger adults does not represent a transition into non-offending adulthood (Loughran et al. 2009). As proposed by the deterrence theory, the current study proposes the system punish youth more severely because punishment is used as a deterrence to prevent future offending in later adulthood.

Loughran et al. (2009) indicated there was no marginal benefit for additional length of stay to reduce the future rate of re-arrest for individuals who received institutional placement. However, a future rate of recidivism, or the type of institution for punishment, is not the primary focus in the current study. Specifically, the goal of the current study is to determine whether adolescents receive a longer length of sentence than an adult for the same type of crime; therefore, elements in the current research, such as age, sex, and type of crime highlight 
important components that Loughran et al. (2009) failed to include. For example, their research neither included adults nor females, which would not fully explain the hypothesis in the current study; because there is a comparison between the amount of punishment for younger and older individuals, as well as males and females. Whereas, their study failed to evaluate specific violent and property crimes, the current study examines two specific categories from violent and property crime. Failure to identify the specific crime an individual commits only neglects researchers of the specific amount of punishment for a specific crime.

\section{Empirical Review: Age and Offending}

The main independent variable in the current study is age. The goal of the current research is to determine whether age affects the amount of punishment. As noted in previous sections, age tends to be a variable that is measured for the various types of crimes an individual commits. The current study examines several articles that have studied age and rates of offending to better explain age and crime. For example, similar to the current hypothesis that age affects punishment, MacDonald et al. (2009) studied the amount of punishment based on age.

MacDonald et al. (2009) examined self-reported criminal offending—violent and nonviolent - over the course of one year. The authors provided a close-up inspection of one-year changes in offending among ages 13 to 17, "which the researchers argued is the age range during which many young offenders establish lifelong patterns of crime or desistance from crime” (MacDonald et al. 2009). Data from a number of studies indicate that both violent and nonviolent crime peak during those years (MacDonald et al. 2009). "Whereas, this approach limits generalizability to changes that might be observed over a longer time period, or at a different age 
range, it offers the advantage of detailed inspection of change during a period noted for its dynamism” (Farrington 1986; Loeber and Farrington 1998; MacDonald et al. 2009).

Whereas, MacDonald et al. (2009) only provided a one-year change in offending among the ages 13 to 17, the life course theory states this is not the peak of a criminal career, and more precisely, an individual's criminal career does not peak until their early 20's. However, the current study proposes that this particular age group (youth) receives a lengthier amount of punishment to deter a criminal peak in an individual's early adulthood. MacDonald et al. (2009) solely examined adolescents and the offending pathways for violent and non-violent crimes as a whole. Additionally, MacDonald et al. (2009) argued past research demonstrates that majority of adolescents commit crimes with their peers, and their research focused and represented the amount of peer delinquent association. While peers are an important consideration in delinquency involvement, the current study does not identify peer association because the focus is on age and the amount of punishment for adolescents and adults.

Although, MacDonald et al. (2009) focused on adolescents that committed violent and non-violent crimes, and argued that crime peaks for the ages of 13 to 17, other researchers have demonstrated a considerably larger age sample to measure criminal careers. Francis et al. (2007) examined a person's criminal career path and the changes throughout an individual's criminal career length. In the authors attempt to model career length, they used only information available at the start of an "official" criminal career (Francis et al. 2007). There were six definitions to better explain some of their chosen variables, but the two main variables that relate to age in the current study are: (1) Start of an official criminal career, which relates to the first court 
conviction and is the start of an official career; and (2) age at first conviction, which were categorized into five categories, ranging from 10 to 14 to 30 and older.

Francis et al. (2007) specified the length of an individual's criminal career as the dependent variable in the study. The length of an individual's criminal career is continuous and determines when a criminal career becomes terminated. Past research (Blumstein et al. 1982; Kazzemian 2007) has addressed the same issues. In regards to the study conducted by Francis et al. (2007), they considered a criminal career as terminated if there were no further convictions five years after the date of the last conviction. Recent research, however, demonstrates that individuals with a crime-free period of five to seven years tend to appear as non-offenders (Kurlychek et al. 2006). The length of a criminal career was determined as the time between the first conviction and the last conviction (Francis et al. 2007). For each offender, the authors defined the event of interest to be the termination of the criminal career, "which occurred for some offenders and not for others” (Francis et al. 2007). The main result the authors' found was that after controlling for covariates representing the initial conviction, the risk of desistance remained constant during a period of 20 to 25 years, if the offender did not stop immediately after their first conviction (Francis et al. 2007).

Similar to the focus on age of onset represented by MacDonald et al. (2009), Bacon et al. (2009) conducted a test of the causal significance on the age of onset for criminal offending with data from the 1958 Philadelphia cohort study. Bacon et al. (2009) indicated that individuals who initiated early offending displayed higher probabilities of offending than those who initiated later in life. The authors stated that early age of onset was inversely associated with a higher risk of later criminal behavior. Bacon et al. (2009) relates to the current study because they examined 
the significance of the age of onset for criminal offending. However, age is the independent variable in the current study and assists to explain the relationship between age and the amount of punishment for adolescents and adults. The authors stated the peak ages of offending were 15 and 16. The type of offenses for both adolescents and adults is a measure in the current study, but the main focus is the amount of punishment for both age categories. The authors' displayed that early age of onset was associated with a higher risk of criminal behavior. Also, the authors' findings could be important to the current research because it may assists to explain the number of offenses for youth and adults, as well as if prior jail time increases the likelihood the CJS punish youth more severely for a crime committed at a younger age.

To understand the comparison between age and arrest trends, Armstrong (2008) examined and demonstrated that age was the main factor to determine arrest rates. Armstrong's analysis revealed that, although, controls for age did not account for trends in specialization across all types of offending, age did appear to have an important influence on trends in specialization for particular offense types. The finding demonstrated that many of the trends in specialization across offenses found in earlier work (Blumstein et al, 1988; Lattimore et al., 1994; Stander et al., 1989) were influenced by age-driven changes in the tendency to specialize. In the case of property and violent offenses, trends across arrests prior to the introduction on controls for age were positive, while trends after controls for age were negative (Armstrong 2008).

The main comparison between Armstrong's research and the current study is the focus on age; however, the current study can add to the research of Armstrong (2008). The author only focused on an age group of 24 to 35, which ignored the juvenile population. The main 
component of the current research is the relationship between age and the amount of punishment. Both, Armstrong and the current study, compare the type of crime and the age of the offender; however, the main focus in the current study is the amount of punishment for the different age groups.

\section{Empirical Review: Prior Jail and Prior Prison Time}

The current study controls for prior jail time to determine if an individual was previously incarcerated. This is important because prior incarceration may affect the amount of punishment for adolescents and adults. Three articles, outlined below, that control for previous incarceration explains why prior incarceration is a measure in the current study. Similar to the focus on prior incarceration, Bacon et al. (2009) noted the importance of prior offending in their research for the age of onset and criminal careers. Although, it is not linked specifically to punishment, the authors indicated that individuals who initiated offending early in life have higher probabilities of offending than those who initiated later in life (Bacon et al. 2009). This is important to the current study because a control for prior jail time assists to determine if there are any effects on the amount of punishment for either an adolescent or adults.

According to research on criminal careers, prior offending has importantly been linked to the type of received punishment. In a study focused on modeling career length, Francis et al. (2007) obtained only information available at the start of an "official” criminal career. Although, the current study does not specifically examine the criminal careers, the information presented by Francis et al. (2007) assists with the current study because the authors' examined each conviction and the most severe punishment an individual received based on multiple offenses. The main 
objective of their study was to explain the number of offenses an individual had previously committed to receive a harsher punishment. The findings of Francis et al. (2007) indicated an important link between prior offenses and length of punishment. Francis et al. (2007) displayed the relationship between prior incarceration and amount of punishment was further complicated when the age of the offender was considered. The main objective of the research conducted by Wiesner et al. (2003) was to explain that early intervention in adolescent years is needed to prevent adult criminal careers.

Although, early intervention is not the main objective if the current study, I do state that youth are punished more severely than adults for the same type of crime to prevent future criminal offending. There may be a link between their research and the current research because Francis et al. (2007) conclude that contact with the CJS was significant for juvenile arrests, but not adult arrest. This particular finding in the study of Francis et al. (2007) may offer support for the current hypothesis that the CJS punish youth more harshly than adults for each crime. The current research, when controlling for prior offenses, aims to determine if the amount of punishment for youth at their initial contact is harsher than the punishment for adults.

\section{Empirical Review: Demographic Characteristics in Life Course Theory}

Several demographic measures are consistently included in research on the relationship between age and crime, including education, race, and gender. Education is frequently included as a control variable in research that focuses on punishment, recidivism, and criminal careers (Wiesner et al. 2003; Loughran et al. 2009). Education level was a control variable in the research of Wiesner et al. (2003) and Loughran et al. (2009) because majority of researchers use a variety of measures for education in their research to determine the amount of literacy an 
individual possess. More specifically, Wiesner et al. (2003) measured education as a variable to explain an individual's educational background versus their criminal background, whereas, Loughran et al. (2009) measured the amount of education for the adolescent's parents. Both Wiesner et al. (2003) and Loughran et al. (2009) conclude education was significant in their study. In the current study, I control for education to determine its effects with age and the amount of punishment. One limitation in the research of Loughran et al. (2009) was that they measured the amount of education each individual's parents possessed to explain recidivism and placement. I do not measure the amount of education for each individual's parents because I focus on the amount of criminal activity for an individual, not their parent; therefore, it is not necessary to measure a parent’s education level.

Race is, also, an important demographic variable to include in research because it is important to know if a specific ethnicity is responsible for the most crime committed, and what ethnicity receives the longest sentence based on specific crimes. Controlling for race accounts for differences in race that could be affecting the lengths of sentence imposed for offenders. One important thing to notice in the research conducted by Bacon et al. (2009), was the relatively close relationship between whites and non-whites in the study, which consisted of 51.3 percent classified as non-white and 48.7 percent classified as white. In the Bacon et al. (2009) research, there was not a large difference between offenders being white and non-white. In the current study, I recoded race as white or non-white.

Finally, the demographic measure of sex is a variable in the current research to measure which gender group commits specific types of crime. Gender is found important, with females approaching a 40 percent higher risk of stopping than males, in the research of Francis et al. 
(2008). This is important to note because it could represent that females are not punished as harshly as males. Research, outlined above, has failed to include females in their study (Bacon et al. 2009; Bouffard et al. 2003; Loughran et al. 2009; Wiesner et al. 2003). One important thing to notice in regards to the variables from Loughran et al. (2009) is the sample failed to include females in the study. The authors' neglected to run an analysis on females to determine whether their recidivism rates were higher due to a placement in a setting, or if their recidivism rates were likely to be higher due to the amount of days served in the placement. Another study that failed to include females in their sample is Wiesner et al. (2003). It is important to include both genders in any research to adequately explain the amount of punishment for both males and females based on a specific crime.

\section{Type of Offense}

The most important contribution of the current research is the inclusion of a specific violent or property offense an individual commits. I select specific offenses from both violent and property crimes; whereas, past research mainly groups violent and property crimes as a whole. More specifically, I measure aggravated assault and robbery as violent offenses and burglary and larceny as property offenses. It is beneficial to study specific types of crimes from each category because it better explains what age group commits a certain type of crime; and also, better explains the amount of punishment for a specific type of crime. Researchers have studied crimes as a whole, which only distinguished if a person committed a violent or nonviolent crime. This could be a potential problem because it neglects to specify what types of crimes are committed most frequently. Furthermore, it neglects to explain the age group that commits specific types of violent or property crimes and the amount of punishment for a specific 
crime. The main component of the current study is the break-down of offenses to determine the age and amount of punishment for that offense. Outlined below, are articles that better explain why specific offenses were chosen for the current research, how each study defined crime, the distinction between property and violent crime, and the specific types of crime from each category.

MacDonald et al. (2009) estimated crime into two categories: (1) violent crimes; and (2) non-violent crimes. Their study failed to break-down a distinct type of crime an individual committed; and in turn, only labeled an individual as either a violent or non-violent offender. MacDonald et al. (2009) defined crime as antisocial behaviors that lead to violence and aggression. In their study, they defined both violent and non-violent crimes as the same type of behavior because there was no consensus on whether the propensity was different between the two types of crime. Specifically, the authors' failed to examine the specific type of violent or non-violent crime an individual committed. This is problematic because MacDonald et al. (2009) "proposed it was not necessary to divide the two categories because each type of crime contains the same underlying factors on why they are considered to be a crime”.

The current research adds to the research of MacDonald et al. (2009) because a particular crime, the age of the individual who committed the crime and the amount of punishment are all accounted for. The current research determines if younger individuals are more likely to be punished more severely for one specific crime than adults. Furthermore, MacDonald et al. (2009) failed to include adults in their study; therefore, the authors' only tested the offending pathway of violent and non-violent offenses for adolescents. 
Similar to MacDonald et al. (2009), Lee et al. (2009) included only violent crime as a measure to determine stability throughout a neighborhood based on increases and decreases in population. Lee et al. (2009) constructed the index of violent crime rates, per 100,000 people, by averaging murder, robbery, and aggravated assault rates over the years of 1980 to 1982 . The study did not include property crimes in their research, whereas the current study includes property crime to assist in the explanation for the amount of punishment based on both violent and property crimes. However, the authors' main objective of the study was to determine if population size affected crime.

Unlike Lee et al. (2009), Francis et al. (2007) included property crime as on offense in their sample. Their findings stated that individuals who began their career with a burglary offense, as opposed to a different type of offense, were more likely to repeat crime after incarceration. Individuals charged with burglary had a higher risk of continuous crime and a longer criminal career (Francis et al. 2007). Thus, the authors estimated the offender with the longest criminal career to be a male who began his criminal career at the age of 15 or younger with a burglary offense (Francis et al. 2007). The current study hypothesizes the amount of punishment, depending on the age at the individual's conviction, and assists in explaining the age and punishment relationship. For example, Francis et al. (2007) demonstrated that an adolescent who committed burglary was less likely to desist from crime and future repeat offenses of burglary. Burglary is one of the property offenses in the current study; therefore, it may be beneficial to the findings.

In regards to specific offense types, Armstrong (2008) demonstrated the influence of age on trends in specialization across offense was particularly important for property and violent 
offense. This is important to the current study for two reasons: (1) age may affect the type of crime committed; and (2) the length of punishment may vary depending on the age and type of offense. All articles, outlined above, offer a range of evidence that is useful to examine specific categories of crime, which is highlighted as importance in the current study.

\section{PLAN OF STUDY}

The main goal of the current research is to determine if younger individuals received a harsher punishment than older individuals for the same type of crime. Elements from the deterrence and labeling theory, as well as elements from the life course theory, are a framework in understanding the reasoning for a younger individual receiving a greater amount of punishment than an older individual. The elements from the deterrence theory are important in the current research because it states that harsh punishment threatens and deters future offending. The elements from the labeling theory are important in the current research because it explains that harsh punishment for young individuals labels them as a criminal and they accept and portray that label. Elements from the life course theory are important in the current research because an incorporation of the amount of punishment relates specifically to a transition in an individual's criminal career.

The hypothesis in the current study is that younger individuals are punished more severely than older individuals for the same type of crime. I hypothesize that youth are punished more severely than adults, based on elements from the deterrence, labeling, and life course theory. Deterrence theory states the type of punishment an individual receives aides in deterrence for future offending. This is important because it supports the hypothesis that younger 
individuals are punished more severely to prevent the individual from repeating crime later in adulthood. The labeling theory states that a label stigmatizes an individual and he or she repeat crime and become a continuous criminal offender. This theory offers support for the hypothesis because prior incarceration assist to explain that once an individual is incarcerated and labeled as a criminal, he or she continue to fulfill the role. The life course theory states once an individual commits a crime at a young age, he or she continues to commit crime into adulthood. This supports the hypothesis because the life course theory states that age is important to understand crime and punishment.

I display descriptive statistics to present the sample size, mean, and standard deviation of the variables. I examine bivariate correlations to present a relationship between two variables to explain if there is a relationship between the two specific variables. I analyze multivariate regression because it determines if younger individuals receive a harsher punishment than older individuals. Also, multivariate regression demonstrates what happens when only the independent and dependent variable is accounted for, as well as demonstrates how the control variables affect the relationship between the independent and dependent variable.

\section{DATA AND MEASURES}

Data for this study were obtained through a secondary analysis of the National Corrections Reporting Program (NCRP), in the United States, 2003. The National Corrections Reporting Program gathered data on prisoners entering and leaving the custody of supervision of state and federal authorities. The dataset was comprised of three parts of data: (Part 1) prisoners who were admitted to prison; (Part 2) prisoners released from prison; and (Part 3) prisoners 
released from parole. The NCRP applied uniform measurement rules to the data for the states, using the following concepts and definitions: (1) prison $^{1}$; (2) calendar year reporting ${ }^{2}$; (3) custody criteria for prison admissions and releases ${ }^{3}$; (4) jurisdiction criteria for parole releases ${ }^{4}$; (5) prisoner movements ${ }^{5}$; and (6) parole and mandatory parole release. ${ }^{6}$

The NCRP reported that majority of the archived database evolved from the need to improve and consolidate data on corrections at the national level. The objective was to provide a consistent and comprehensive description of prisoners entering and leaving the custody, or supervision of state and federal authorities. Although, the NCRP data does not clearly represent the number of repeat offenses each inmate had committed throughout their life, the data did provide information on the type of offenses and prior jail time served for each inmate. The instrument used in the cross-sectional component of the NCRP data was a self-reported questionnaire $^{7}$. The NCRP data only specified the timing of distribution for the questionnaires to be throughout the calendar year of 2003.

\section{SAMPLE}

\footnotetext{
${ }^{1}$ Prison is defined as a state or federal correctional facility that has custodial authority over persons sentenced to confinement.

${ }^{2}$ Calendar year reporting is defined as the data collected for the total number of admissions and releases from prison, as well as the number of parole releases in the year January 1, 2003 through December 31, 2003.

${ }^{3}$ Custody criteria for prison admissions and releases were defined as the data collected on all prisoners admitted or released while under the physical custody for state correctional authorities.

${ }^{4}$ Jurisdiction criteria for parole releases were defined as information reported on those offenders under the jurisdiction of the paroling authority.

${ }^{5}$ Prisoner movements were defined as any prisoner movements that either increased or decreased the custody counts of each reporting state.

${ }^{6}$ Parole and mandatory parole release were defined as the status of an offender who was released from to community supervision.

${ }^{7}$ Cross-sectional data refers to data collected by observing many subjects at the same time.
} 
Questionnaires were used to indicate the information requested on prisoners admitted to prison, released from prison, and released from parole in the calendar year of 2003. The data were submitted on computer tapes, micro floppy disks, CD’s, or manually prepared forms. There were 40 states, plus the California Youth Authority, that reported data for $2003 .{ }^{8}$ The overall data for the NCRP analysis consisted of 559,526 individuals admitted to prison in 2003, 542,867 individuals released from prison in 2003, and 309,302 individuals’ parole released in 2003. However, the overall data was reduced for the current study because of limited information available for the length of punishment variable. The length of punishment variable constrained the sample for the current study to one state, Illinois, and a sample size of 32,099. Although, the research focus narrows the number of offenders in the analysis, the sample includes the most representative sample available.

\section{VARIABLES}

The dependent variable measured the total time inmates were sentenced to incarceration to determine if youth were punished more severely than adults. Total punishment served is a continuous variable and measures the length of punishment for both youth and adults. The independent variable was age at admission, and recoded into four categories: (1) less than eighteen, which is youth; (2) greater than 18 and less than 25- early adulthood; (3) greater than 25 and less than 50 — middle adulthood; and (4) greater than 50 and less than 99—late adulthood. Age at admission was divided into four categories to better capture the length of

\footnotetext{
${ }^{8}$ Alabama, Alaska, Arkansas, California, Colorado, Connecticut, Florida, Georgia, Hawaii, Illinois, Iowa, Kentucky, Louisiana, Maine, Maryland, Massachusetts, Michigan, Minnesota, Mississippi, Missouri, Nebraska, Nevada, New Hampshire, New Jersey, New York, North Carolina, North Dakota, Oklahoma, Oregon, Pennsylvania, Rhode Island, South Carolina, South Dakota, Tennessee, Texas, Utah, Vermont, Virginia, Washington, West Virginia and Wisconsin.
} 
punishment given to a particular age group. The main objective of the current study is to study whether youth were punished more severely than adults; therefore, it is necessary to have an age category that is specifically for youth, which was 18 and less.

Prior jail time, education, race, sex, and four offense types represent the control variables in the current study. Prior jail was not recoded because it was previously measured in months. It is important to include previous offenses as a control variable because the theories, outlined above, states that particular age groups, especially adolescents, were more likely to continue in criminal behavior throughout their life. Prior incarceration may also influence the sentence length of their current offense. Education was recoded into three categories: (1) less than $11^{\text {th }}$ grade; (2) $12^{\text {th }}$ grade or GED; and (3) some college or college degree. It is important to control for education to determine if the individual that committed the crime is educated, or illiterate, because that could influence the path of their criminal career. The race variable was recoded into white (coded 1) or non-white (coded 0 ). All respondents of a minority race are in the reference category because the sample size in the data for the minority races was very small. Sex was recoded into males, which was either male (coded 1) or non-male (coded 0).

There is a measure of the two types of property and two types of violent crimes in the current study. Burglary and larceny were measured for property crimes, and robbery and aggravated assault were measured for violent crimes. The break-down for the two types of offenses is important because past research mainly tests property and violent crimes as a whole, which leaves question as to what specific type of crime an individual commits. Not only did the study measure the amount of punishment for youth and adults, but it also examined if the punishment was harsher for a specific type of crime. This can add to research in two ways: (1) 
the CJS will better understand the types of crime a particular age group commits; and (2) to determine if the courts punish youth more severely than adults for the same type of crime.

\section{RESULTS}

The hypothesis for the current study is adolescents are punished more severely than adults for the same type of crime. For this study, descriptive statistics, bivariate correlations, and multivariate regressions were analyzed to determine if the hypothesis is supported. Table 1 presents the overall descriptive statistics, which includes the dependent variable, independent variable, and all control variables.

Table 1. Descriptive Statistics

\begin{tabular}{|c|c|c|c|c|c|}
\hline & $\mathbf{N}$ & Mean & (SD) & Min. & Max. \\
\hline \multicolumn{6}{|l|}{ Dependent Variable } \\
\hline Punishment & 2896 & 124 & 420 & 0 & 368 \\
\hline \multicolumn{6}{|l|}{ Independent Variables } \\
\hline Age & 6750 & 1.69 & 1.95 & 1 & 4 \\
\hline Category $1=18<$ & 121 & & & & \\
\hline Category $2=18-25$ & 2364 & & & & \\
\hline Category $3=25<50$ & 4138 & & & & \\
\hline Category $4=>50<99$ & 123 & & & & \\
\hline \multicolumn{6}{|l|}{ Control Variables } \\
\hline Prior Jail Time (months) & 6746 & 1.68 & 1.08 & 0 & 12 \\
\hline Education & 4812 & 1.20 & 808 & 1 & 3 \\
\hline Category $1=<11$ th Grade & 2565 & & & & \\
\hline Category 2= 12th Grade or GED & 1740 & & & & \\
\hline Category 3= Some College/College Degree & 507 & & & & \\
\hline White & 2298 & .340 & .473 & 0 & 1 \\
\hline Male & 6373 & .944 & .229 & 0 & 1 \\
\hline \multicolumn{6}{|l|}{ Offenses } \\
\hline Robbery & 1684 & .249 & .432 & 0 & 1 \\
\hline Aggravated Assault & 1710 & .253 & .434 & 0 & 1 \\
\hline Burglary & 3002 & .444 & .496 & 0 & 1 \\
\hline Larceny & 354 & .052 & .222 & 0 & 1 \\
\hline
\end{tabular}


Table 1 illustrates the age-punishment relationship and presents findings that individuals incarcerated served an average of 29 months. In addition, the main independent variable-agewas broken down into four categories to better represent what age group served the most time incarcerated. The age groups were broken down based on elements of the life course theory, which indicate that crime increases and decreases at certain points in an individual's life. Out of the sample $(\mathrm{N}=6,750)$ for the four crimes (robbery, aggravated assault, burglary, and larceny), the majority of the inmates fell into age category 3, ages 25 to $49(\mathrm{~N}=4,138)$. Most other respondents were in category 2, which includes inmates ages 18 to $25(\mathrm{~N}=2,364)$. It is important to notice the small difference between age categories 1 and 4 . Age category 4 (ages $>50<99$ ) consists of 123 offenders $(\mathrm{N}=123)$ and age category $1(18<)$ consists of 121 respondents $(\mathrm{N}=$ 121). According to the prior jail time variable, inmates previously served an average of 7 months in jail. The findings relate to the life course theory element that once an individual begins to commit crime, their chances to repeat offenses are greater (Sampson and Laub 1993).

In this study, I controlled for demographic variables that included education, race, and gender. Out of the sample $(\mathrm{N}=4,812)$ for education, majority of the inmates appeared in category $1(\mathrm{~N}=2,565)$, which was coded as less than $11^{\text {th }}$ grade. Category 2 for education, followed behind category 1 , with a sample of $N=1,740$, which was $12^{\text {th }}$ grade or GED. Category 3 for education, displayed the lowest number of respondents $(\mathrm{N}=507)$, which represents that a very small percentage of the sample possessed a higher education degree. Table 1, also, illustrates that over half of the inmates incarcerated were male (94\%). Also, less than half of the population in the sample was white (34\%). 
For the following four offenses — robbery, aggravated assault, burglary, and larcenyTable 1 indicates that majority of the inmates were incarcerated for a burglary offense (44\%). Also, in Table 1, robbery and aggravated assault consists of about the same population (25\%) and larceny arrestees made up about (5.2\%) of the population. Overall, Table 1 presents that around $50 \%$ of the inmates were incarcerated for a violent offense (robbery or aggravated assault) and around 50\% of the inmates were incarcerated for a property crime (burglary and larceny, with burglary carrying around 44\%).

Table 2. Descriptives for Types of Offense

\begin{tabular}{|c|c|c|c|c|c|c|c|c|c|c|c|c|}
\hline & \multicolumn{3}{|c|}{ Robbery } & \multicolumn{3}{|c|}{ Agg Assault } & \multicolumn{6}{|c|}{ Burglary Larceny } \\
\hline & $\mathbf{N}$ & Mean & (SD) & $\mathbf{N}$ & Mean & (SD) & $\mathbf{N}$ & Mean & (SD) & $\mathbf{N}$ & Mean & (SD) \\
\hline \multicolumn{13}{|l|}{ Dependent Variable } \\
\hline Punishment & 622 & 39.23 & 33.52 & 890 & 16.95 & 16.55 & 1168 & 25.09 & 20.89 & 176 & 11.55 & 7.92 \\
\hline \multicolumn{13}{|l|}{ Independent Variables } \\
\hline Age & 1683 & 2.52 & .578 & 1710 & 2.69 & .527 & 2999 & 2.65 & .542 & 354 & 2.77 & .524 \\
\hline Category $1=18<$ & 56 & & & 17 & & & 46 & & & 2 & & \\
\hline Category $2=18-25$ & 740 & & & 528 & & & 1003 & & & 93 & & \\
\hline Category $3=25<50$ & 873 & & & 1126 & & & 1895 & & & 244 & & \\
\hline Category $4=>50<99$ & 14 & & & 39 & & & 55 & & & 15 & & \\
\hline \multicolumn{13}{|l|}{ Control Variables } \\
\hline Prior Jail Time (months) & 1684 & 7.53 & 7.32 & 1710 & 5.05 & 5.87 & 3002 & .951 & .217 & 354 & 4.07 & 3.87 \\
\hline Education & 1169 & 1.57 & .681 & 1134 & 1.55 & .657 & 2241 & 1.58 & .676 & 268 & 1.68 & .709 \\
\hline Category $1=<11$ th Grade & 633 & & & 619 & & & 1189 & & & 124 & & \\
\hline Category $2=12$ th Grade or GED & 409 & & & 411 & & & 814 & & & 106 & & \\
\hline Category 3= Some College/College Degree & 127 & & & 104 & & & 238 & & & 38 & & \\
\hline White & 272 & .162 & .368 & 633 & .370 & .483 & 1235 & .411 & .493 & 158 & .446 & .498 \\
\hline Male & 1608 & .951 & .215 & 1595 & .933 & .251 & 2854 & .951 & .217 & 322 & .909 & .287 \\
\hline
\end{tabular}

Table 2 represents the overall descriptive statistics that included the sample size, the mean, and the standard deviation for inmates within each of the four offense categories. Table 2 presents the age categories that represent the age group that committed the most of each offense. Table 2 displays the same distribution, across all four offense types, for age categories 3 and 2. Each offense reports that individuals predominately fell into the age category 3 (ages 25 - <50), 
followed by age category 2 (ages 18 -25). In regards to the age categories 1 and 4 , all offense types, with the exception of robbery, contained more offenders in age category $4(>50<99)$ than age category $1(18<)$. Robbery contained more offenders in age category 1 , than age category 4 . It is important to notice the robbery offense consisted of the most youth $(\mathrm{N}=56)$; and, age category 1 for robbery was relatively higher than age category 4 . In regards to the offense of burglary, age category $1(\mathrm{~N}=46)$ and age category $4(\mathrm{~N}=55)$ were only separated by a difference of 9 individuals.

Table 2 displays inmates that served a prior jail time conviction before their current offense. Inmates incarcerated for their current conviction of a violent offense were more likely to have served prior jail time than inmates incarcerated for their current conviction of a property offense. Individuals incarcerated for robbery served roughly 8 months prior jail time and the inmates incarcerated for aggravated assault served roughly 5 months prior jail time. Individuals incarcerated for larceny served roughly 4 months prior jail time and inmates incarcerated for burglary were less likely to serve prior jail time.

Table 2 reports the amount of education each inmate possessed at the time they were imprisoned for one of the four offenses. The pattern of education is the same across all four offense types. Most offenders incarcerated fell into category $1\left(<11^{\text {th }}\right.$ grade), followed by category 2 (12 ${ }^{\text {th }}$ grade or GED), and few offenders for both violent and property crimes fell into category 3(Some college/College degree). Although, categories 1 and 2 of education followed fairly closely for robbery, aggravated assault, and burglary, larceny displayed the closest numbers for education categories. Category 1 for larceny consisted of N=124 individuals and category 2 contained $\mathrm{N}=106$ individuals. There was only a difference of 18 individuals for the 
two age categories, whereas, the other three offense types had over a 200 individual difference for the two categories.

Also, Table 2 exhibits the demographic measures of race and sex. Both property offenses in the data present similar findings for race. For the offense of larceny, the sample consisted of about $45 \%$ whites, which was almost half of the sample for larceny. For the offense of burglary, about $41 \%$ of the sample was white. In regards to race and the violent offenses, whites did not dominate the sample. For the offense of robbery, only about $16 \%$ of the population was white; and for the offense of aggravated assault, about $37 \%$ of the sample was white. The demographic measure of sex displayed the same pattern in all four offenses. For both violent offenses, almost every individual in the sample were males (robbery around 95\% and aggravated assault around 93\%). In regards to the property offenses, about $95 \%$ of the offenders incarcerated for burglary were males and the larceny sample consisted of about $91 \%$ males.

Table 2 illustrates that out of the four offense types, individuals served more time incarcerated for robbery (around 39 months). Individuals served around 25 months for a burglary offense, followed by aggravated assault (around 17 months), and larceny received the least amount of punishment (around 12 months). In Table 2, the data presents that a property crime offender (burglary) received a lengthier punishment than a violent crime offender (aggravated assault). Considering larceny is the intent to deprive an individual of their belongings, without intending any harm, individuals received only 5 months less (around 12 months) than an offender convicted of a violent crime of aggravated assault (around 17 months). 
Table 3 presents the bivariate correlation analysis based on the variables in the study. The most important aspect of this chart is the correlation between age and punishment. For each unit increase in age, there was a unit decrease in the amount of punishment, which represents that older offenders served less time than younger offenders (-.079). For each unit increase in prior jail time, an individual received .455 of an increase on their amount of punishment. The relationship between education and punishment length was negative and suggest individuals with less education are more apt to serve a longer sentence. In terms of demographic characteristics, whites received a shorter sentence than minorities and males served longer sentences than females.

The bivariate correlation depicts important differences in the amount of punishment for different types of crime. Inmates incarcerated for robbery received more on their length of sentence than those incarcerated for aggravated assault, burglary, and larceny (.151). Inmates incarcerated for burglary served more time than those incarcerated for aggravated assault and larceny (.051). Respondents were likely to serve less time when incarcerated for aggravated assault (-.032) or larceny (-.035).

Table 3, also, presents the relationship between age and prior incarceration. Older offenders were more likely to serve prior incarceration than younger offenders (.011). The relationship between age and two offense types (robbery and burglary) was negative and presents that each increase in the age variable represents a decrease in the type of offense variable. Additionally, Table 3 indicates that inmates incarcerated for robbery, aggravated assault, and burglary were more likely to serve prior jail time than those incarcerated for larceny. 
Table 3. Correlations

\begin{tabular}{|c|c|c|c|c|c|c|c|c|c|c|}
\hline & 1 & 2 & 3 & 4 & & 5 & 6 & 7 & 8 & 9 \\
\hline \multicolumn{11}{|l|}{1 Punishment } \\
\hline 2 Age & $-.079 * * *$ & & & & & & & & & \\
\hline 3 Prior Jail Time & $.455 * * *$ & $.011^{* *}$ & & & & & & & & \\
\hline 4 Education & $-.020 * * *$ & $.172 * * *$ & .003 & & & & & & & \\
\hline 5 White & $-.047 * * *$ & $.006 * *$ & $-.120 * * *$ & .113 & $* * *$ & & & & & \\
\hline 6 Male & $.098 * * *$ & $-.097 * * *$ & $.068 * * *$ & -.032 & $* * *$ & $-.011 * *$ & & & & \\
\hline 7 Robbery & $.151 * * *$ & $-.097 * * *$ & $.099 * * *$ & -.006 & & $-.054 * * *$ & $.044 * * *$ & & & \\
\hline 8 Aggravated Assault & $-.032 * * *$ & -.013 & .001 & -.013 & $* *$ & $.057 * * *$ & $.031 * * *$ & $-.056 * * *$ & & \\
\hline 9 Burglary & $.051 * * *$ & $-.043 * * *$ & .000 & -.004 & & $.108 * * *$ & $.060 * * *$ & $-.076 * * *$ & $-.076 * * *$ & \\
\hline 10 Larceny & $-.035 * * *$ & .009 & $-.017^{* * *}$ & .015 & $* *$ & $.044 * * *$ & .006 & $-.025 * * *$ & $-.025 * * *$ & $-.034 * * *$ \\
\hline
\end{tabular}

Table 4 presents the multivariate regression analysis for the amount of punishment and robbery. Table 4 includes 2 models. The first model includes the main relationship between the independent and dependent variables. The second model includes the relationship between the independent and dependent variable, when controlling for race, gender, education, and prior incarceration. Model 1, only, illustrates the results of regression between the independent variable of age and the dependent variable of punishment. Model 1 indicates that each unit increase in age category represents, roughly, a 9 month decrease in amount of punishment, which supports my hypothesis. Model 1 includes age as the independent variable to explain the relationship between the independent and dependent variable. It is important to test how age alone affects punishment, as this is the relationship highlighted by the life course theory.

Model 2 presents regression results after all control variables were included. Model 2 reports that each unit increase in age represents, roughly, an 8 month decrease in length of punishment, when controlling for demographic variables and prior incarceration. The significant relationship between age and punishment, in Model 2, supports my hypothesis. Prior jail time is significant and represents that for each unit increase in prior jail time, there is a 2 month increase 
on the current length of sentence. Also, noted in Model 2, males received roughly 8 additional months on their amount of punishment than females. Finally, Model 2 demonstrates that whites received an additional 2 months on the amount of punishment than minorities, and there is no significance to the relationship. Controlling for race did not represent a predictable factor between the dependent and independent variables because race was not significant in Table 4. It is important to include the type of offense in this model to examine how specific types of crime influence the relationship between the age of the offender and the amount of punishment. Table 4 presents a significant relationship for robbery at the .001 level, which demonstrates that robbery is a reliable indicator between the dependent and independent variables. Overall, Table 4 presents support for the hypothesis.

Less than $2 \%$ of the variance of the dependent variable, amount of punishment, is explained by the independent variable, age, in Model 1. In Model 2, about 25\% of the variance in the amount of punishment is explained by the independent variable, along with all control variables. The variance increased after the control variables were added to the regression and better explained factors that contributed to the age-punishment relationship.

Table 4. Linear Regression for Robbery

\begin{tabular}{lrrrr}
\hline & Model 1 & Model 2 & \\
\hline Constant & 48.39 & $* * *$ & 24.09 & $* * *$ \\
Age Group & -8.99 & $* * *$ & -7.54 & $* * *$ \\
Prior Jail Time & & & 2.42 & $* * *$ \\
Education & & & .583 & \\
Whites & & & 1.519 & \\
Males & & & 7.93 & $* * *$ \\
Robbery & & & 17.11 & $* * *$ \\
\hline N & & & 8642 & \\
R-Sq & 8642 & & .250 & \\
\hline
\end{tabular}

$* p<.05, * * p<.01$, $* * * p<.001$ 
Table 5 presents the regression results for aggravated assault. In Model 1, of Table 5, only the independent variable of age is regressed on the dependent variable of punishment. In Model 2, Table 5, I controlled for demographic variables and prior incarceration. Model 1 presents a significant relationship that as age increases the amount of punishment decreases. In Model 1, older individuals served roughly 9 additional months than younger individuals. In Model 2, for each unit increase in age there is roughly an 8 month decrease in the amount of punishment and the relationship was significant. In both models, of Table 5, there is a significant relationship between the dependent and independent variables and demonstrates that a significant proportion of the variability between variables is explained.

In Model 2, all control variables and prior incarceration were compared. Prior jail time is significant at the .001 level, which indicates a strong significance, or verification between the dependent and independent variables, and represents that each unit increase in prior jail time added an additional 3 months to the length of sentence for the new offense. Model 2 presents that males roughly received an additional 8 months on their amount of punishment over females and the relationship is significant at the .001 level. Less than $2 \%$ of the variance for the dependent variable is explained in Model 1, Table 5, and about 24\% of the variance is explained in Model 2 of Table 5. However, both models, in Table 5, support the hypothesis and demonstrate that younger offenders received additional months on their amount of punishment, as compared to older offenders. Aggravated assault was significant at the .001 level and presents that aggravated assault is a reliable indicator between the dependent and independent variable relationship.

Table 5. Linear Regression for Aggravated Assault 


\begin{tabular}{|c|c|c|c|c|}
\hline & Model 1 & & Model 2 & \\
\hline Constant & 48.39 & $* * *$ & 26.79 & $* * *$ \\
\hline Age Group & -8.99 & $* * *$ & -8.35 & $* * *$ \\
\hline Prior Jail Time & & & 2.47 & $* * *$ \\
\hline Education & & & .650 & \\
\hline Whites & & & 1.46 & \\
\hline Males & & & 8.32 & $* * *$ \\
\hline Aggravated Assault & & & -5.91 & $* * *$ \\
\hline$N$ & 8642 & & 8642 & \\
\hline $\mathrm{R}-\mathrm{Sq}$ & .018 & & .242 & \\
\hline
\end{tabular}

Table 6 presents the multivariate results for offenders convicted of burglary. Model 1, Table 6, demonstrates that for each unit increase in age, an individual served about 9 months less incarcerated for burglary and that relationship is significant at the .001 level. Although, Model 1 displays support for the hypothesis, only about $2 \%$ of the variance, of punishment, is explained by the independent variable of age, which is not a good explanation for the age-punishment relationship.

In model 2, Table 6, the hypothesis is supported and represents that younger individuals served an additional 8 months incarcerated than older people. Also, in Model 2, there is a significant relationship between prior jail time and punishment. More specifically, individuals received an additional 2 months on their current length of punishment if he or she served previous jail time. Whites only served an additional month than non-whites incarcerated and this relationship is not significant. Males served an additional 8 months for punishment than females, and that relationship is significant at the .001 level. The variance in the length of punishment explained by the independent and control variables increased to about 24\% in Model 2. Burglary 
is significant on the .001 level in Model 2 of Table 6 and displayed that burglary is a significant indicator between the age-punishment relationship.

Table 6. Linear Regression for Burglary

\begin{tabular}{lrrrr}
\hline & Model 1 & & Model 2 & \\
\hline Constant & 48.39 & $* * *$ & 26.15 & $* * *$ \\
Age Group & -8.99 & $* * *$ & -8.24 & $* * *$ \\
Prior Jail Time & & & 2.46 & $* * *$ \\
Education & & & .737 & \\
Whites & & & 1.09 & \\
Males & & & 8.02 & $* * *$ \\
Burglary & & & 3.13 & $* * *$ \\
\hline N & & & 8642 & \\
R-Sq & 8642 & & .241 & \\
\hline
\end{tabular}

${ }^{*} \mathrm{p}<.05, * * \mathrm{p}<.01$, $* * * p<.001$

Table 7 presents the results from the regression for larceny. For Model 1, there was a significant relationship between age and punishment. Model 1 illustrates that for each unit increase in age, the amount of punishment decreased about 9 months. In Model 2, the relationship between age and punishment was very similar to Model 1 and displayed that for each unit increase in age, individuals served about 8 months less time incarcerated. Both models in Table 7 depict a significant age-punishment relationship that represents strong variability in the variables.

In Model 2, prior jail time is significant and represents that individuals who served prior jail time received an additional 3 months on their length of punishment. Whites only served around an additional month incarcerated than non-whites and this relationship is not significant. Males served an additional 8 months incarcerated for larceny than females. The amount of variance in Model 1 explained less than 2\% of the variance in the length of punishment. About 
24\% of the variance in Model 2 was explained by age, prior incarceration, and demographic variables. Larceny is significant at the .001 level and represents that larceny is a reliable indicator between the age-punishment relationship. The hypothesis is supported in Table 7 because as an individual aged, the amount of punishment decreased by about 9 months.

Table 7. Linear Regression for Larceny

\begin{tabular}{|c|c|c|c|c|}
\hline & Model 1 & & Model 2 & \\
\hline Constant & 48.39 & $* * *$ & 24.49 & $* * *$ \\
\hline Age Group & -8.99 & $* * *$ & -8.31 & $* * *$ \\
\hline Prior Jail Time & & & 2.47 & $* * *$ \\
\hline Education & & & .719 & \\
\hline Whites & & & 1.35 & \\
\hline Males & & & 8.22 & $* * *$ \\
\hline Larceny & & & -8.62 & $* * *$ \\
\hline$N$ & 8642 & & 8642 & \\
\hline $\mathrm{R}-\mathrm{Sq}$ & .018 & & .240 & \\
\hline
\end{tabular}

\section{DISCUSSION}

The purpose of this study was to examine a relationship between age and punishment, with elements from the deterrence theory, labeling theory, and life course theory as a framework. Youth are punished more harshly than adults for the same type of crime was the hypothesis tested in the study. The results present support for the theoretical ideas and highlight the importance of examining the length of punishment for specific types of crimes. The data conclude the age-punishment relationship to be significant and support the hypothesis in the regression models for all offenses. Although, the length of sentence youth received was not excessively harsher than that of adults (roughly 9 months longer), it provided support for the hypothesis. 
Prior jail time proved to be significant at the .001 level, in the regression models, for all offense types. In regards to the results that present prior jail time was significant and offenders received additional months on their current conviction, these results represent minimal support for the theoretical ideas of the deterrence theory. This finding was not an affective form of deterrence for any offender because almost the entire sample had prior jail time convictions. The fear of punishment is not a reliable deterrent for the offenders in this dataset because majority of the sample, almost 100\%, served prior jail time incarceration and later became reconvicted for a crime. These results suggest that punishment is not likely to deter future offending.

One explanation to describe why deterrence is not effective in this study, in regards to prior jail incarceration, is the possibility that young offenders may not deter from crime in fear of punishment because they did not receive a "harsh" punishment at their first conviction. More specifically, and represented in the results, repeat offenders may continue to offend because they do not feel threatened by the received punishment for the crime. Instead, offenders consider their conviction to be a "slap on the wrist." Outlined in the literature section above, McGrath (2009) identified perceptions of deterrence to play an important role in the recidivism rates of individuals. Although, this study did not measure perceptions of deterrence, it is consistent with previous literature that the deterrent effect had minimal impact on future recidivism rates (Watkins et al. 2008; McGrath 2009). In this study, the results did yield adequate results to demonstrate that almost the entire sample is considered repeat offenders. Furthermore, the results from this study yield support the CJS enforced harsh punishment on youth to deter future offending. The length of punishment displays a longer sentence for younger offenders across all offense types. 
Past research on labeling theory states that once an individual commits a criminal act and receives a "criminal” label, he or she become stigmatized by the negative label, and begin to fulfill the role as a criminal (Tapia 2010; McGrath 2009). Consistent with past labeling theory research (Tapia 2010), the results revealed evidence to support the theoretical ideas behind negative stigmatization. Researchers argue that labels such as "criminal or juvenile delinquent" are negatively stigmatizing on individuals and those labels are more likely to trigger deviant behavior and cause reoffending (Bernburg et al. 2006). This study presents information that the sample was classified as repeat offenders that will continue to subsequentially commit crime, due to the negative labels placed upon them by society for delinquent acts. The sample, almost $100 \%$, demonstrates that offenders were previously incarcerated and supports theoretical ideas from the labeling theory that once an individual is labeled as a criminal they succumb to that criminal role.

According to the life course theory, trajectories explain continuity of criminal activity in an individual's life and represent prior incarceration rates. The results from the current study are consistent with life course theory because almost the entire sample served previous jail time, prior to their current conviction, and trajectories are used to explain recidivism rates for an offender (Sampson and Laub 1993; Piquero 2005). These findings relate to previous life course research that presents importance between prior offending and arrests rates (Wiesner et al. 2003; Francis et al. 2007; Armstrong 2008; Bacon et al. 2009). It is important to measure prior incarceration, within the life course theory, because the theory states that continuity and change in behavior is linked to past events. Francis et al. (2007) examined specific types of crime to test the relationship between crime and the length of an individual's criminal career to better explain 
the life course theory. Although, I did not examine criminal careers and outcomes in this study, the results the prior jail time variable presents adds to the life course research that concentrates on criminal careers because I used life course transitions and trajectories to explain punishment. It is important in this study on punishment to include prior incarceration because the goal is to determine if prior incarceration has an effect on an individual's current conviction. Controlling for prior jail time in the study demonstrates that almost all of the offenders in the sample were repeat offenders. The results relate to previous life course research that studied criminal careers because it verifies further validity that the offenders in this sample were on the trajectory path of continuity in crime.

Also, represented by the life course theory, transitions explain a specific event in an individual's life, such as crime (Sampson and Laub 1993; Piquero 2005). Opposed to the life course theory literature that stated crime is more likely to peak in early adulthood and that offenders do not receive a harsh punishment until their mid-twenties, the results in this study present that age category $3(25<50)$ contained the most offenders across all offense types. Furthermore, the results demonstrate that for each unit increase in age, the length of punishment decreased, which also contradicts with the life course theory that stated offenders do not receive a harsh punishment until the near end of their criminal careers (Sampson and Laub 1993).

A break-down of general crime to violent and property, as done in two articles mentioned above (MacDonald et al. 2009; Armstrong 2008), is useful because it displays a specific type of crime an individual commits. It is important to break-down general crime into violent and property because it presents the characteristics of each type of crime. For example, violent crimes are classified as murder and non-negligent manslaughter, forcible rape, robbery, and 
aggravated assault. Property crimes are classified as burglary, larceny, theft, motor vehicle theft, arson, shoplifting, and vandalism. The characteristics that separate violent crime from property crime is that violent crimes involve force and threat against another human; whereas, property crime consist of an individual depriving another individual of their personal belongings. However, according to the findings, further break-down into specific types of offenses indicate a better explanation of the specific type of crime a particular age category commits, as well as the amount of punishment for that offense.

I defined robbery and aggravated assault as violent crimes based on there characteristics. The two types of violent crime differ because robbery is defined as the attack or attempt to attack an individual using force; and, aggravated assault is defined as the attack on an individual using force to cause severe or aggravated bodily injury. Although, robbery and aggravated assault are classified as two different crimes, each crime shares the similarity of attacking an individual. I defined burglary and larceny as property crimes because burglary is the intent to enter a place to commit an offense; and, larceny is a form of theft. My results yield a better explanation to previous life course literature (Armstrong 2008; MacDonald et al. 2009) because the data specifically represents the type of violent or property crime committed and, then, presents the amount of punishment for that particular crime. It is important that specific crimes are identified as either violent or property crimes because this is a contribution to past life course theory research that examined violent and property crimes as a whole; therefore, these results represent a better explanation for the age-punishment relationship based on crime.

One explanation for the findings that robbery and burglary are significant and positive in the models relates to past research (Francis et al. 2007) that states individuals who begin their 
career with a burglary offense are more likely to repeat crime after their current incarceration. Past research of Francis et al. (2007) presented evidence that individuals charged with a burglary offense, had a higher risk of continuous crime and a longer criminal career, especially in regards to males who begin their criminal careers at age 15 or younger. The findings represented in Table 3 displayed that demographic variables further clarify the age-punishment relationship. In regards to the similarities between robbery and burglary offenses, Table 3 displayed the strength in punishment for those two offenses when all predictors, or demographic variables, were measured. The findings of the current study is an addition to the research of Francis et al. (2007) because as the amount of punishment increases for robbery and burglary offenses, so does the age of the offender.

One explanation for the findings that aggravated assault and larceny are significant and negative in the models is the similarities between specific demographic variables. Both offense types present a small difference between age categories 4 and 1, with age category 4 holding the most offenders. Also, both offense types present a similarity in education, with category 1 having the most offenders. In regards to punishment, there was a five month difference in the amount of punishment, with aggravated assault presenting five additional months on the length of punishment than larceny. Table 3 displayed the similarities between aggravated assault and larceny offenses when all predictors, or demographic variables, were measured. According to Illinois statutes, offenders convicted of a felony crime serve a minimum of one year; and, the current data revealed that offenders convicted of aggravated assault served around, but not exactly, 12 months. 
Previous research (Wiesner et al. 2003; Loughran et al. 2009) identified the importance of education in the elements of the life course theory. In two studies, mentioned above, the authors determined education to be a significant factor. The results in the current study add to the authors' research because education did not have a significant relationship with punishment for a specific crime. It is important to recognize that education displayed no significance, for any offense, when it is used as a control variable because there is no significant variability in education that explains the length of punishment. These results suggest the amount of education one possesses is not considered during a conviction and adds to the literature that education has no effect in the type of crime committed and the amount of punishment. This finding in the current study is important because it displays that other variables, such as prior jail time, have more of an effect on the amount of punishment than education. These results are an addition to the literature because the CJS is possibly dismissing education as a factor because the primary goal is to punish an individual for crime, and focus on education either during or after release.

Bacon et al. (2009) presented the importance of race in the elements of the life course theory. The results in this study displayed no significance across all offense types between the race-punishment relationship. It is important to recognize that race displays no significance for any offense because race is not a good predictor for the amount of punishment an individual received at conviction. These results suggest that race is not accounted for during an individual's conviction and adds to the literature that race has no effect on age, the type of crime committed and the amount of punishment. Over half of the respondents were non-white, but race did not yield a significant relationship between race and the amount of punishment. This finding is important because society is geared toward believing that minorities receive a lengthier 
punishment than whites because majority of minority groups are poverty-stricken and live in inner cities where crime often occurs.

Francis et al. (2008) noted the importance of gender in the elements of the life course theory. The results in the current study presented evidence that males roughly received 8 additional months on their punishment over females. Gender was significant across all offense types and demonstrates that gender did affect the length of punishment for the crime committed. However, previous research, noted above (Bacon et al. 2009; Bouffard et al. 2003; Wiesner et al. 2003; Loughran et al. 2009), failed to include females in their study. This study is an addition to the authors' literature because both males and females are accounted for in my study to determine that males received a longer length of punishment than females.

These findings represent my main contribution to the literature on deterrence theory, labeling theory, and the life course theory. The result from the study that is an addition to the elements from the deterrence theory is that majority of the offender population, almost $100 \%$, had prior convictions that resulted in jail time. The results yield that punishment alone, is not a main ingredient to deter reoffending. The results from the study that adds support to the labeling theory, is the finding that negative stigmatization of criminal labels result in recidivism. My results display that after an individual received incarceration for a crime committed, he or she reoffended and received punishment for the current offense. The result from my study that is an addition to the elements of the life course theory is that almost the entire sample is on a trajectory of continuity in crime. My results demonstrate the age-punishment relationship to serve as trajectories in offenders' life because of recidivism in the sample. 


\section{LIMITATIONS AND FUTURE RESEARCH}

That data for my study were obtained from the NCRP. Each year, the NCRP distributes the same questionnaire, across all states, to gather information on inmates incarcerated. Because the NCRP dataset includes data from across the U.S., elements such as who conducted the investigations and the type of methods used could affect the information obtained; and therefore, affect accurate information for all variables in the dataset. In my study, to determine if youth were punished more severely than adults for the same type of crime, I only included one state, Illinois, in my sample due to the lack of information for the punishment variable in all states. Researchers would state that my results were not truly a nationally representative sample because the sample size was $N=6,750$. In the future, the NCRP should closely monitor each questionnaire to assure there is information available for each variable in the dataset. The NCRP could monitor the questionnaires closely through distribution to inmates in their cells, or distribution to inmates in classroom, etc. This study is an example of information that is not distributed or collected properly because I had to narrow the sample size to one state that contained information for every variable necessary to determine the outcomes of my hypothesis.

Future research should examine the age at each conviction for all prior and current offenses to better understand the age-punishment relationship. One limitation in this research is the NCRP data set did not offer information for the age at conviction for prior incarceration. It would be beneficial when studying the life course theory to know the age at each conviction to better determine if the individual is on a path to desist from crime. Another limitation in the research is that I recoded age into four categories and failed to discover a more accurate age of the offenders at the time of their conviction. A better break-down of age would explain more 
elements in the deterrence and life course theory, such as the exact age a harsh punishment is enforced.

Although, many studies have tested elements from the deterrence, labeling, and the life course theory, and discovered that age is significant in relation to elements of a person's criminal career, minimal research has studied specific types of crime to better explain the amount of crime a specific age group commits. I focused on four types of offenses to address this gap in the literature. Future research could look at a variety of offenses, beyond the four included in the current study, and measure age and punishment to better examine the life course theory. Finally, the main focus of this research was to determine if the CJS punished youth more severely than adults for the same types of crime. This is beneficial to future research on life course theory because researchers can incorporate how the amount of punishment relates to a specific crime and discover mechanisms to enforce the right amount of punishment for that crime to reduce recidivism rates.

Despite these considerations, the current research documents the amount of punishment between youth and adult offenders, and the inclusion of multiple measures of prior incarceration, demographic variables, and type of offense. In addition, this research used a sample for understanding the relationship between age and punishment. The same findings emerged in all four offense types and represented support for the hypothesis that youth are punished more severely than adults for the same type of crime. The key finding is that offenders seemed impervious to deterrence messages and were on a trajectory path to a life of continuous criminal activity. Clearly, this group of offenders were not reached effectively, due to almost all having 
prior incarceration records. These findings suggest the challenges to better understand harsher punishment for youth over adults remains a key topic in crime. 


\section{REFERENCES}

Ash, Peter. 2006. “Adolescents in Adult Court: Does the Punishment fit the Criminal?” Journal of the American Academy of Psychiatry and the Law Online 34(2): 145-149.

Armstrong, Todd A. 2008. “Are Trends in Specialization across Arrest explained by Changes in Specialization Occurring with Age.” Justice Quarterly 25: 201-222.

Bacon, Sarah, Raymond Paternoster, and Robert Brame. 2009. "Understanding the Relationship between Onset Age and Subsequent Offending During Adolescence.” Journal of Youth and Adolescence 38: 301-311.

Bernburg, J.G., M.D. Krohn, and C.J.Rivera. 2006. Official Labeling, Criminal Embeddedness, and Subsequent Delinquency: A Longitudinal Test of Labeling Theory. Journal of Research in Crime and Delinquency 43: 67-90.

Bilchick, Shay. 2000.”Challenging the Myths.” Juvenile Justice and Delinquency Prevention.

Blumstein, Alfred. 2003. Age, crime, and human development: The future of life-course Criminology. Presidential Plenary Session, discussant paper presented at the annual meeting of the American Sociology of Criminology, Denver, Co.

Blumstein, Alfred, Jacqueline Cohen, and David P. Farrington. 1988. "Criminal career research: Its value for criminology.” Criminology 26:1-35.

Bouffard, Leana Allen and Nicole Piquero. 2003. "Defiance Theory and Life Course Explanations of Persistent Offending.” Crime and Delinquency 56: 227-252.

Brame, Robert, Raymond Paternoster and Shawn D. Bushway.2004. "Criminal Offending Frequency and Offense Switching.” Journal of Contemporary Criminal Justice 20: 201214.

Cauffman, E., Steinberg, L., and Piquero, A. 2005. "Psychological, neuropsychological, and psychophysiological correlates of serious antisocial behavior in adolescence: The role of self-control.” Criminology 43: 133-176.

Fagan, J. 1996. “The comparative advantages of juvenile vs. criminal court sanctions on recidivism among adolescent felony offenders.” Law and Policy 18: 77-114.

Fagan, J. 1999. “Punishment or Treatment for Adolescent Offenders?” Therapeutic Integrity and the Paradoxical Effects of Punishment. Quinnipiac Law Review18: 502. 
Francis, Brian, Keith Soothill, and Alex R. Piquero. 2007. "Estimation Issues and Generational Changes in Modeling Criminal Career Length in Modeling Criminal Career.” Crime and Delinquency 53: 84-105.

Gottfredson, Denise C. and David A. Soule. 2005. "The Timing of Property Crime, Violent Crime, and Substance Use among Juveniles.”

Gove, W. 1980. “The Labeling of Deviance: Evaluating a Perspective.” New York: Sage.

Kleck, G., Sever, B., Li, S., and Gertz M. 2005. “The Missing Link in General Deterrence Research.”Criminology 43: 623-659.

Laub, John II., and Robert J. Sampson. 1993. “Turning points in the life course: Why change matters to the study of crime?” Criminology 31:301-25.

Lee, Matthew A. and Shaun A. Thomas. 2009. "Civic Community, Population Change, and Violent Crime in Rural Communities.” Crime and Delinquency 47: 118-147.

Loughran, Thomas A., Edward P. Mulvey, Carol A. Schubert, Jeffrey Fagan, Alex R. Piquero, and Sandra H. Losoya. 2009. "Estimating a Dose-Response Relationship between length of stay and future Recidivism in Serious Juvenile Offenders.” Criminology 47: 699-740.

MacDonald, John H., Amelia Haviland, and Andrew R. Morral. 2009. “Assessing the Relationship between Violent and Non-Violent Criminal Activity Among Serious Adolescent Offenders.” Journal of Research in Crime and Delinquency 47: 553-580.

McGrath, Andrew. 2009. Offenders’ Perceptions of the Sentencing Process: A Study of Deterrence and Stigmatization in the New South Wales Children's Court. The Australian and New Zealand Journal of Criminology 42: 24-46.

Moffitt, Terrie E. 1993. Adolescence-limited and life-course persistent antisocial behavior: A developmental taxonomy. Psychological Review 100:674-701.

Moffitt, T.E., Lynam, D.R., and Sylva, P.A. 1994. "Neuropsychological tests predicting persistent male delinquency.” Criminology 32: 277-300.

Nagin, Daniel S. 1998. "Criminal Deterrence Research at the Outset of the Twenty-first Center." Crime and Justice: An annual review of research 23: 1-42.

Nagin, Daniel S. 2005. Group-based modeling of development. Cambridge, MA: Harvard University Press.

Piquero, A. 2001. “Testing Moffitt's neuropsychological variation hypothesis for the prediction of life-course persistent offending.” Psychology, Crime, and Law 7:193-216. 
Paternoster, R. and L. Jovanni. 1989. The Labeling Perspective and Delinquency: An Elaboration of the Theory and an Assessment of the Evidence. Justice Quarterly 6: 359394.

Piquero, Alex. 2005. "What have we learned about the natural history of criminal offending through longitudinal studies?” Paper presented at the National Institute of Justice, Washington, DC.

Piquero, A., Blumstein, A., Brame, B., Haapanen, R., Mulvey, E., and Nagin, D. 2001. "Assessing the impact of exposure time and incapacitation on longitudinal trajectories of criminal offending.” Journal of Adolescent Research 16: 54-74.

Piquero, Alex R., David P Farrington, and Alfred Blumstein. 2003. The criminal career paradigm: Background and recent developments. Crime and justice: A review of Research 30: 359-406.

Piquero, A.R., and White, N.A. 2003. On the relationship between cognitive abilities and life course-persistent offending among a sample of African Americans: A longitudinal test of Moffitt’s hypothesis. Journal of Criminal Justice 31: 399- 409.

Pogarsky, Greg, Alex R. Piquero, and Raymond Paternoster. 2004. Modeling change in perceptions about sanction threats: The neglected linkage in deterrence theory. Journal of Quantitative Criminology 20:344-369.

Pogarsky, Greg. 2007. "Deterrence and Individual Difference among Convicted Offenders.” Journal of Quantitative Criminology 23: 59-74.

Roper v Simmons. 2005.

Saltzman, Mark. 2004. True Notebooks: A Writer’s Year at Juvenile Hall.

Sickmund, Melissa. 2004. Juveniles in Corrections. Washington, DC: U.S. Department of Justice, Office of Juvenile Justice and Delinquency Prevention, NCJ 202885.

Sampson, Robert J., and John II. Laub. 1993. Crime in the making: Pathways and turning points through life. Cambridge, MA: Harvard University Press.

Sampson, Robert J., and Laub, John H. 2003. "Life-course desisters?” Trajectories of crime among delinquent boys followed to age 70. Criminology 41: 301-399.

Stahlkopf, Christina, Mike Males, and Daniel Macallair. 2008. Testing Incapacitation Theory: Youth Crime and Incarceration in California. Crime and Delinquency 56: 253-268.

Tapia, Michael. 2010. “Untangling race and class effects on juvenile arrest.” Journal of Criminal Justice 38: 255-265. 
Watkins Adam M., Huebner Beth M., and Scott H. Decker. 2008. Patterns of Gun Acquisition, and Use Among Juvenile and Adult Arrestees: Evidence from a High-Crime City. Justice Quarterly 25: 674-700.

Wiesner, Margit, Hyoun Kim, and Deborah Capaldi. 2003. "History of Juvenile Arrests and Vocational Career Outcomes for At-Risk Young Men.” Crime and Delinquency 47: 91117.

Zimring, F., and Hawkins, G. 1996. Lethal Violence and the Overreach of American Imprisonment. Report presented at the Annual Research and Evaluation Conference of the National Institute of Justice, Washington, DC. 